\title{
Review \\ A Review of Recent Advancements in Offshore Wind Turbine Technology
}

\author{
Taimoor Asim ${ }^{1, *(\mathbb{D}}$, Sheikh Zahidul Islam $\left.{ }^{1}{ }^{(}\right)$, Arman Hemmati ${ }^{2}{ }^{-}$and Muhammad Saif Ullah Khalid ${ }^{2}$ \\ 1 School of Engineering, Robert Gordon University, Aberdeen AB10 7GJ, UK; s.z.islam1@rgu.ac.uk \\ 2 Department of Mechanical Engineering, University of Alberta, Edmonton, AB T6G 1H9, Canada; \\ arman.hemmati@ualberta.ca (A.H.); mkhalid1@ualberta.ca (M.S.U.K.) \\ * Correspondence: t.asim@rgu.ac.uk; Tel.: +44-1224-262457
}

check for updates

Citation: Asim, T.; Islam, S.Z.; Hemmati, A.; Khalid, M.S.U. A Review of Recent Advancements in Offshore Wind Turbine Technology. Energies 2022, 15, 579. https:// doi.org/10.3390/en15020579

Academic Editor: Filippo

Campaginolo

Received: 25 October 2021

Accepted: 10 January 2022

Published: 14 January 2022

Publisher's Note: MDPI stays neutral with regard to jurisdictional claims in published maps and institutional affiliations.

Copyright: (C) 2022 by the authors. Licensee MDPI, Basel, Switzerland. This article is an open access article distributed under the terms and conditions of the Creative Commons Attribution (CC BY) license (https:// creativecommons.org/licenses/by/ $4.0 /)$.

\begin{abstract}
Offshore wind turbines are becoming increasingly popular due to their higher wind energy harnessing capabilities and lower visual pollution. Researchers around the globe have been reporting significant scientific advancements in offshore wind turbines technology, addressing key issues, such as aerodynamic characteristics of turbine blades, dynamic response of the turbine, structural integrity of the turbine foundation, design of the mooring cables, ground scouring and cost modelling for commercial viability. These investigations range from component-level design and analysis to system-level response and optimization using a multitude of analytical, empirical and numerical techniques. With such wide-ranging studies available in the public domain, there is a need to carry out an extensive yet critical literature review on the recent advancements in offshore wind turbine technology. Offshore wind turbine blades' aerodynamics and the structural integrity of offshore wind turbines are of particular importance, which can lead towards system's optimal design and operation, leading to reduced maintenance costs. Thus, in this study, our focus is to highlight key knowledge gaps in the scientific investigations on offshore wind turbines' aerodynamic and structural response. It is envisaged that this study will pave the way for future concentrated efforts in better understanding the complex behavior of these machines.
\end{abstract}

Keywords: floating offshore wind turbine (FOWT); computational fluid dynamics (CFD); ReynoldsAveraged Navier-Stoke (RANS); structural integrity; finite element analysis (FEA); genetic algorithm (GA); levelized cost of energy (LCoE); maintenance

\section{Introduction}

Offshore wind turbines offer significant benefits over onshore wind turbines. One of the key benefits offshore wind turbines offer is their comparatively bigger size, which translates into lower cost of power generation. Other benefits include lower environmental impacts, more wind energy resource available, etc. The main structure of offshore wind turbines is not very different from onshore wind turbines, as shown in Figure 1. Most commercial offshore wind turbines are horizontal-axis 3-bladed upwind machines, where the above-sea-level components include torque generating blades connected to the hub, which is an integral part of the nacelle. Housed in the nacelle is the main shaft, the gearbox (if applicable) and the generator. Power cables run down from the nacelle through the tower to the supporting structure, which has an outer deck for the operators to gain access to the tower and up to the nacelle. It is noteworthy that for offshore wind harnessing, horizontal axis wind turbines are preferred over vertical axis wind turbines due to their higher wind harnessing capability (bigger commercially affordable size). 


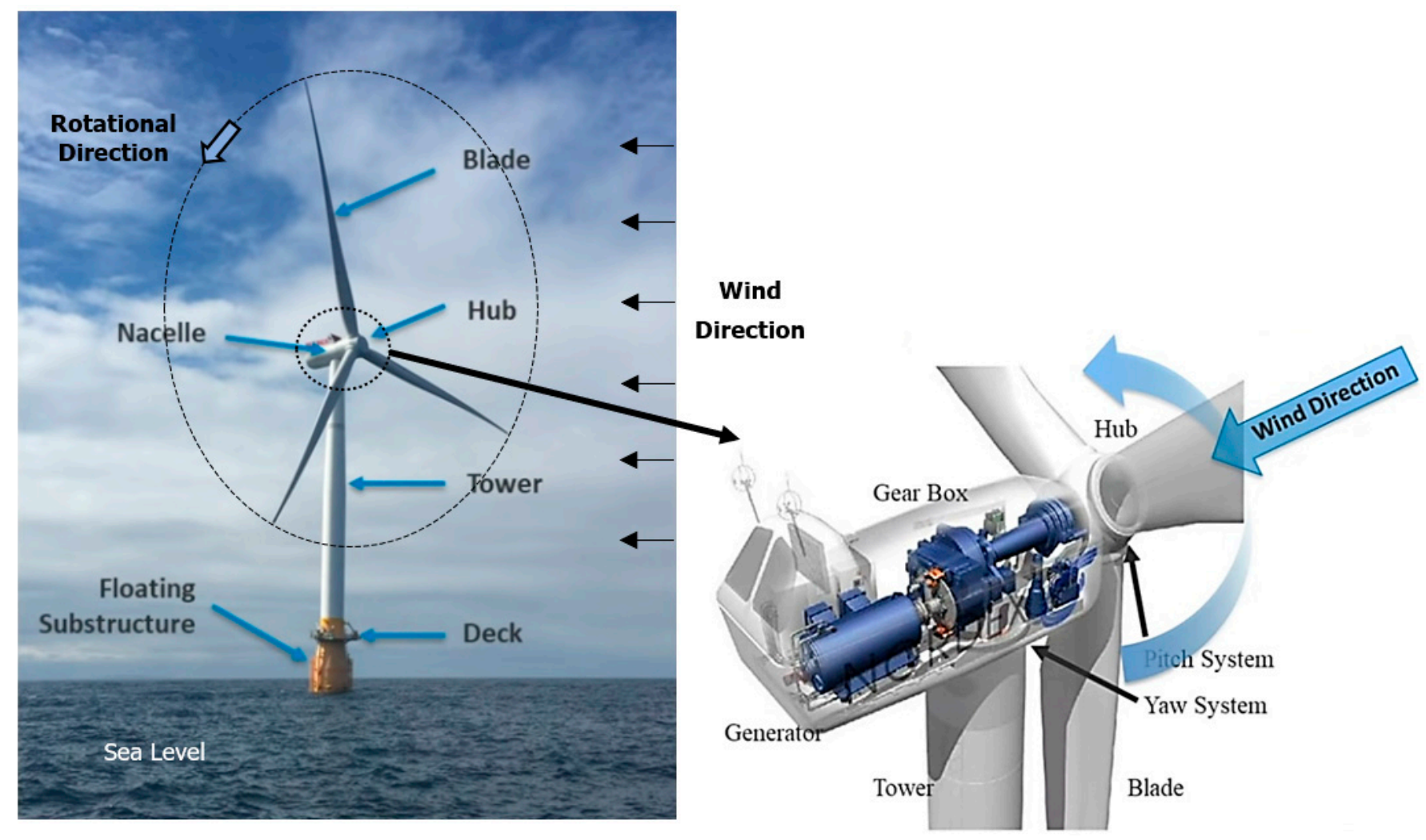

Figure 1. A typical offshore wind turbine (Adapted with permission from ref. [1]. Copyright 2020 Webinar Hosted by National Renewable Energy Laboratory).

The main difference between onshore and offshore wind turbines is how offshore wind turbines are structurally supported. There are broadly two types of offshore wind turbines, i.e., fixed-support and floating. As their names suggest, a fixed-support offshore wind turbine has foundations fixed to the seabed, while floating offshore wind turbines have floating support structures, which are connected to the seabed through mooring cables. Further classification of offshore wind turbines is shown in Figure 2. It can be seen that there are two types of fixed-support offshore turbines in operation commercially, i.e., monopile and jacket. A monopile support consists of a single tower-like structure embedded into the seabed through suction and gravity, whereas jacket support structure comprises of three or four-legged lattice configurations. The primary constraint that fixed-support offshore wind turbines face is that they can be installed in a maximum seabed depth of $60 \mathrm{~m}$. In deep waters (>60 m depth), fixed-support structures become commercially inviable, i.e., cost of installation increases considerably. Most of the commercially installed and operational offshore wind turbines in the world (currently) have fixed-support structures [2]. However, there are some significant issues with this technology. The foremost issue is that more than $80 \%$ of offshore wind energy is available off-coast, i.e., far away from land and in deep waters (seabed depth of $>60 \mathrm{~m}$ ). Another limiting factor of fixed-support wind turbines is their size; the biggest rotor diameter currently installed is $80 \mathrm{~m}$, with the turbine having rated power of 1.8 MW. The visual impact of these type of offshore wind turbines is another factor to be considered seriously. 


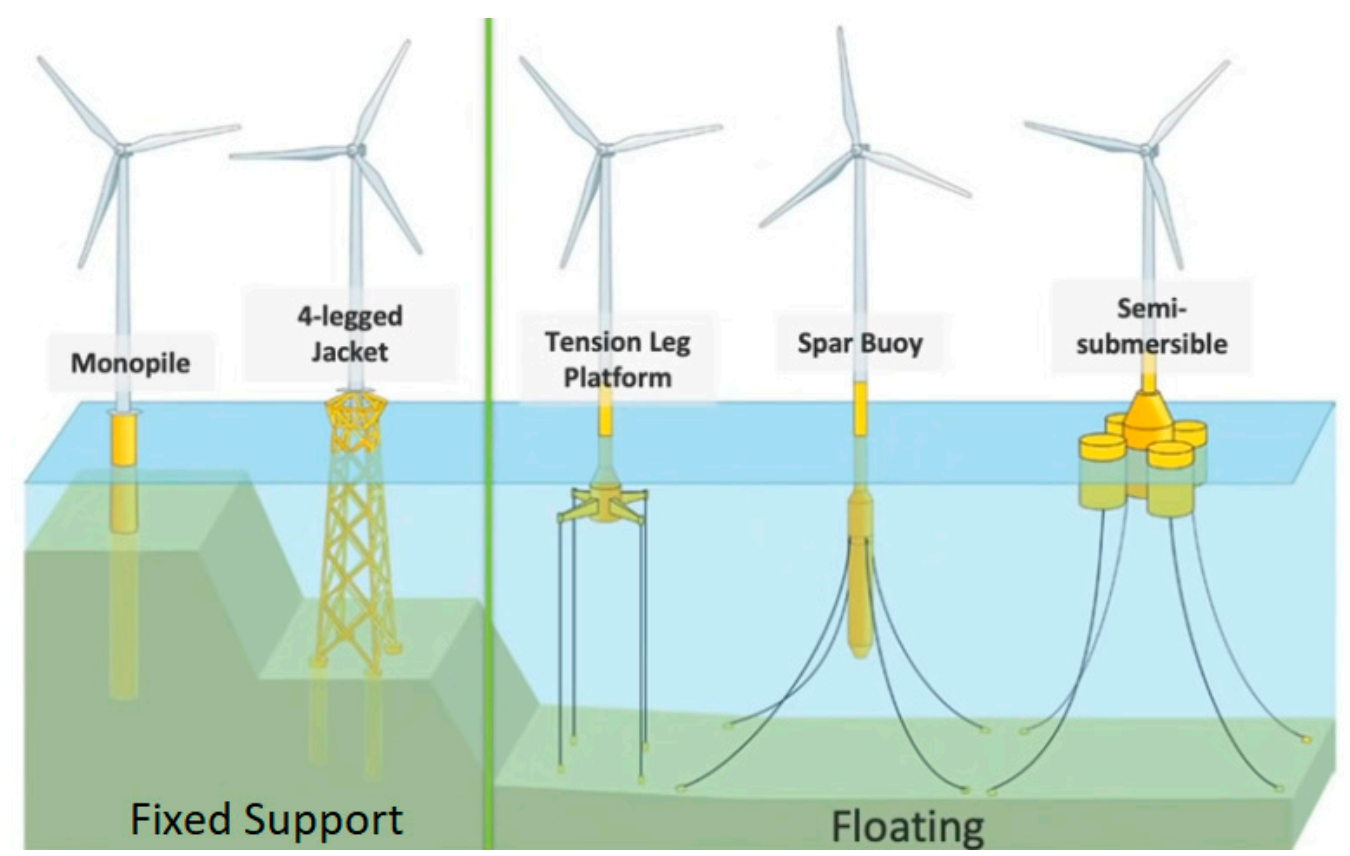

Figure 2. Support structures for offshore wind turbines (Adapted with permission from ref. [1]. Copyright 2020 Webinar Hosted by National Renewable Energy Laboratory).

The three different types of support structures for floating offshore wind turbines are shown in Figure 2. The first one depicted is tension leg support in which three or four mooring cables are connected from the floating substructure to the seabed. The mooring cables are in tension and thus, provide static support to the wind turbine. The limiting factor for this technology is the size of the substructure; if it is too big, the tension in the cables need to be significantly higher and thus, the cost of installation increases. The second type of floating wind turbine's support structure is spar buoy, where a tower-like substructure (sometimes also called as transition piece), filled with ballast, is connected to the seabed through mooring cables. The structural stability under severe weather conditions is an area of ongoing research for these turbines, along with the configuration of the mooring cables. It is noteworthy here that mooring cables are roughly 4 times in length than the seabed depth, thus having considerable costs. The third type of support structure for floating offshore wind turbines is known as semi-submersible, which has many different configurations (only one type shown in Figure 2). The basic idea is to attach buoyant structures with the main substructure (or transition piece). The static structure is achieved through varying the buoyancy in these semi-submersible structures. The floating substructure is connected to the seabed via mooring cables. An important point to note here is that when a floating structure is termed as static, it doesn't mean that it is absolutely stationary. The floating structures of offshore wind turbines are permitted to move freely within a circle, known as watch circle, with a typical diameter of $180 \mathrm{~m}$. The watch circle avoids wind turbine blades experiencing extreme wind loads, which are potentially structurally damaging. However, this introduces another complexity for the mooring cables, i.e., they need to be flexible enough to compensate for the movement of the floating platform [3].

The global market for offshore wind turbines is expected to grow from US $\$ 23 b$ in 2020 to US $\$ 97 b$ by 2027 [4], with major players like Siemens, GE, ENVISION, Northland Power, Ørsted, etc. heavily investing in offshore wind turbine projects. The UK's offshore wind energy market is expected to grow by over $4 \%$ by 2027. It is important to note here that most of the capital investment is made in fixed-support offshore turbine projects. Floating offshore wind turbines offer higher wind harnessing capabilities, albeit higher costs. The first floating offshore wind turbine project, i.e., Hywind, was installed in 2017, 18 miles off the coast of Peterhead (Scotland), comprising of five $6 \mathrm{MW}$ turbines with rotor diameter of $154 \mathrm{~m}$, tower height of $101 \mathrm{~m}$ and seabed depth of between $95 \mathrm{~m}$ and $120 \mathrm{~m}$, costing 
$£ 264 \mathrm{~m}$ [5]. It is important at this stage to understand the commercialization stages of already developed offshore wind turbines. It is a three-stage process [1]:

- Stage 1 Proof of Concept (2009-2016): Offshore wind turbine concepts are developed through funded research;

- Stage 2 Pre-Commercialization (2017-2023): 14 wind farms installed across the globe. Constant monitoring of the machines being carried out;

- Stage 3 Utility-Scale Floating Arrays (2024 onwards): Competitive commercialization of floating wind turbine farms.

A total of $82 \mathrm{MW}$ of floating wind turbines have been installed, with many more under development (such as GE and Siemens). Offshore wind turbine technology is especially important for Scotland as it is one of the five key areas identified for harnessing wind energy economically; others being the east and west coasts of USA and Canada, the east coast of South America and the west coast of Asia (west of China and Japan). Further expanding on the economic viability of offshore wind turbines, it is important to note that the turbine accounts for only $24.3 \%$ of the overall cost of installation of a single offshore turbine. Figure 3 shows a representative cost breakdown for a fixed-support offshore wind turbine project, based on capital expenditure (CapEx) associated with its different components [6]. The various costs shown here have been calculated based on a set of equations obtained after curve-fitting on cost data for different water depths and distances from the port [7], resulting in $\mathrm{R}^{2}$ values of $\sim 95 \%$. The representative offshore wind turbine considered for this purpose is a $3 \mathrm{MW}$ monopile turbine. It can be seen that $26.9 \%$ of the capital costs are associated with the substructures and $18.7 \%$ with the electrical infrastructure. The electrical infrastructure involves different components, such as power cables from individual wind turbines, dynamic array cables, offshore substations, export cable from offshore to onshore substations, onshore substation, etc.

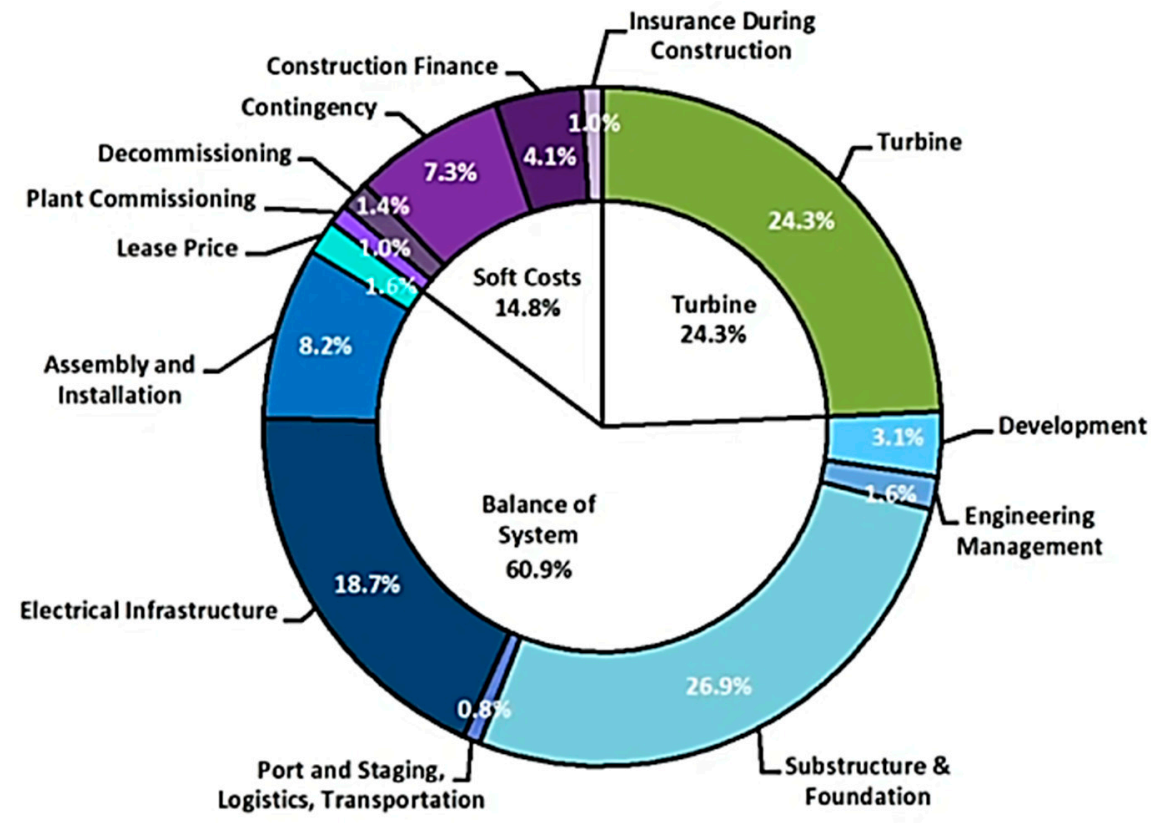

Figure 3. Typical capital costs involved in offshore wind turbine projects (Adapted with permission from ref. [1]. Copyright 2020 Webinar Hosted by National Renewable Energy Laboratory).

There are currently many technological developments regarding offshore wind turbines aimed at reducing the costs involved with the installation of offshore wind farms. These include increasing array voltage to $66 \mathrm{kV}$ for lower costs. It is noteworthy here that electrical array cable cost increases with wind turbine spacing and decreases with their size. However, there is a trade-off in wind turbine spacing between array cable cost and wake losses from the wind turbines. Generally, a spacing of $6 \mathrm{D}$ to $8 \mathrm{D}$ is considered between consecutive offshore wind turbines, where $\mathrm{D}$ is the rotor diameter. The installation cost of 
offshore wind farms, however, is constantly decreasing due to various factors, such as technological improvements. Cost modelling shows a 70\% decrease in the cost of power (per unit) from 2015 to 2025 from fixed-support offshore wind turbines, with floating turbines converging on similar cost of per unit kWh by 2030 [8]. In comparison with onshore wind turbines, it should be noted that a smaller number of turbines produce the same power because offshore wind turbines are bigger in size. A smaller number of turbines are also cheaper to maintain.

The operation and maintenance of offshore wind turbines involve significant costs. According to Rockmann [9], 25-30\% of the total life cycle cost of offshore wind turbines are associated with operation and maintenance. Expanding on offshore wind turbine maintenance, there are two main types, i.e., small and major. Small repairs can be carried out in the field using vessels and remotely operated vehicles (ROVs). This includes repairing and replacing sensors, lubrication, preventive maintenance, etc. For major repairs, offshore wind turbines are normally disconnected from the mooring cables and towing them to onshore facilities. Major repairs include repair of damaged blades, gearboxes, generators, etc. Moreover, recent developments in offshore wind turbine technology are contributing significantly towards lowering the lifecycle costs of offshore wind turbine projects. Potential impacts of technological developments in offshore wind turbine technology are summarized in Table 1.

Table 1. Impact of technological development on offshore wind turbines [9].

\begin{tabular}{lc}
\hline \multicolumn{1}{c}{ Technology Development } & Potential Impact on LCOE \\
\hline Advancements in Rotor Aerodynamics & $-3.70 \%$ \\
Advancements in Turbine Power Rating & $-8.50 \%$ \\
Advancements in Support Structure Design and Installation & $-4.70 \%$ \\
Advancements in Array Optimization & $-1.20 \%$ \\
\hline
\end{tabular}

Based on the aforementioned discussions regarding the offshore wind turbine technology, it is evident that there are three primary mechanical-related areas of recent research. These are offshore wind turbines' (i) flow characterization, (ii) structural integrity and (iii) maintenance. In the present study, we aim to carry out an extensive review of recent advancements in these three broad areas of scientific research.

\section{Flow Characterization of Offshore Wind Turbines}

The complex interactions of blades with the surrounding wind dictates the aerodynamic performance of wind turbines. Thus, it is essential to examine and understand the underlying physical mechanisms associated with their operations. Usually, either experimental or computational methods are adopted to perform such investigations. The later scheme of work can be broadly classified into computational simulations through directly solving incompressible Navier-Stokes (NS) equations. In these approaches, appropriate turbulence modeling strategies or low-order aerodynamic models are incorporated into the computations relying on classic aerodynamic potential flow-based theories and wake models.

The advantage of using experimental techniques is their ability to replicate more realistic conditions for offshore wind turbines. However, maintaining controlled environments to carry out meaningful investigations is a challenging task. Because wind turbines operate with their foundations installed over moving platforms encountering intense wave loads from oceanic water, it changes kinematic conditions of blades having interactions with the on-coming wind. These phenomena add more complexity to the mechanics of such dynamic systems. Important considerations emerge with respect to the aerodynamic performance of wind turbines when they operate in the form of clusters (wind turbine farms). Wave tanks have proven to be effective in quantifying fluidic loads on submersible platforms for different depths. Such a configuration has been employed by Oguz et al. [10], where they found that wave conditions did not significantly impact the response of the plat- 
form. They performed their tests on a $5 \mathrm{MW}$ turbine in a water depth of $70 \mathrm{~m}$. It was also revealed in their experiments that the blade-wind interaction suppressed the pitching motion of the floating platform. Zhou et al. [11] modified the design of a floating wind turbine by integrating wave energy converters in them. Their experiments revealed the damping characteristics of a floating platform. Moreover, Jang et al. [12] investigated an offshore energy harvesting system using a wave basin by generating regular and irregular waves.

Investigating the wake dynamics and its correspondence with the aerodynamic performance of offshore wind turbines involves numerous challenges. These include handling multi-component flows with both air and water, requiring large mesh sizes to capture velocity gradients near blades and near wakes, modeling accurate wave loads on the base of turbines and incorporating atmospheric turbulence for inflows of wind. There are different computational methods for handling movements of a turbine and its base, while dealing with kinematics of turbines with moving platforms. Commonly employed techniques in computational fluid dynamics (CFD) include dynamic meshing [13], overset or Chimera grids [14-18] and sliding mesh technique or arbitrary mesh interfaces (AMI) [19]. Each of these methods has its own strengths and specific limitations. For example, dynamic meshing technique suffers from low-order accuracy and numerical instability due to the generation of mesh elements with poor quality or high skewness. On the contrary, the other two techniques provide more flexibility in terms of maintaining the quality of cells and interpolating flow quantities in different grids. However, preparing appropriate meshes for these computational techniques require skills and expertise.

Full-order CFD simulations can be computationally expensive. It is a common practice in designing wind turbines to rely on low-order modeling techniques based on potential flow models [20] or blade element momentum (BEM) theory [21]. Traditionally, computationally cost-effective simulation frameworks are used, including FLEX, FAST or GH Bladed, which rely on simplistic models, particularly modelling inline forces on bodies interacting with oscillatory flows [22] that remains valid for cylindrical structures with smaller diameters [10]. Despite their low computational cost, they do not handle viscous effects [20], which are important to determine hydrodynamic and aerodynamic features associated with floating foundations, rotating blades, nacelle and tower. Moreover, their capability to model large-amplitude motions and their related phenomena is limited and it involves large deviations from experimental measurements. Liu et al. [13] reported that the commonly used solver FAST, now named OpenFAST, overpredicts aerodynamic performance metrics by 10-20\%. Many investigations coupled CFD-based techniques with either experimental methods or low-order aerodynamic/hydrodynamic models [23]. The primary idea behind these integrated methods is to reduce the computational cost of full-order CFD simulations by modeling different flow characteristics using simpler models. Incorporation of high-fidelity frameworks using full-order computational fluid dynamics-based models in numerical tools for multibody dynamics, such as SIMPACK and MSC ADAMS, would significantly increase the computational cost of these processes, i.e., resource requirement and time. Potential flow-based numerical models cannot capture flow separations around platforms, thus limiting their ability to accurately predict underlying flow physics and its nonlinear dynamic characteristics [10]. Hence, a middle route is taken to utilize the strengths of both approaches to study the behavior of floating offshore wind turbines (FOWTs) [23-25].

Offshore structures usually experience extreme weather conditions, which involve stormy winds and strong waves interacting with the atmospheric boundary layer. To establish the reliability of offshore wind turbines for continuous power generation, it is imperative to understand the impact of turbulent flow conditions on their aerodynamic performance and underlying fluid-structure-acoustic interaction. Traditionally, computational modeling of turbulent flows for these systems involves using various Reynolds-Averaged Navier-Stoke (RANS) equations-based models [13-15,19,24,26-29], large eddy simulations (LES) [30,31], and different versions of detached eddy simulations (DES) [16-18,32]. Other low-order wake models [33] are also introduced along with potential flow-based methods 
to handle unsteady flow dynamics. Recently, a few studies [31,33-36] have been carried out to incorporate the modeling of turbulent wind fields over oceans and irregular wave loads on the floating submersible structures [10]. Primary differences in physical phenomena associated with offshore wind turbines and their urban counterparts include hydrodynamic excitations of foundational platforms. It is due to wave loads and turbulence in the atmospheric boundary layer over oceans, which are graphically shown in Figure 4. There may be other aspects as well, including aero-hydro-elastic interactions and acoustics caused by blades and oscillating platforms due to their complex interactions with wind and water. However, only those stated here are consequential in nature. Hence, this section is planned based on the aforementioned key elements. More details are provided on the state-of-the-art research according to other important factors, which are frequency-based modeling of wave loads, numerical modeling for control techniques, clusters and farms of FOWTs and flow-induced acoustics.

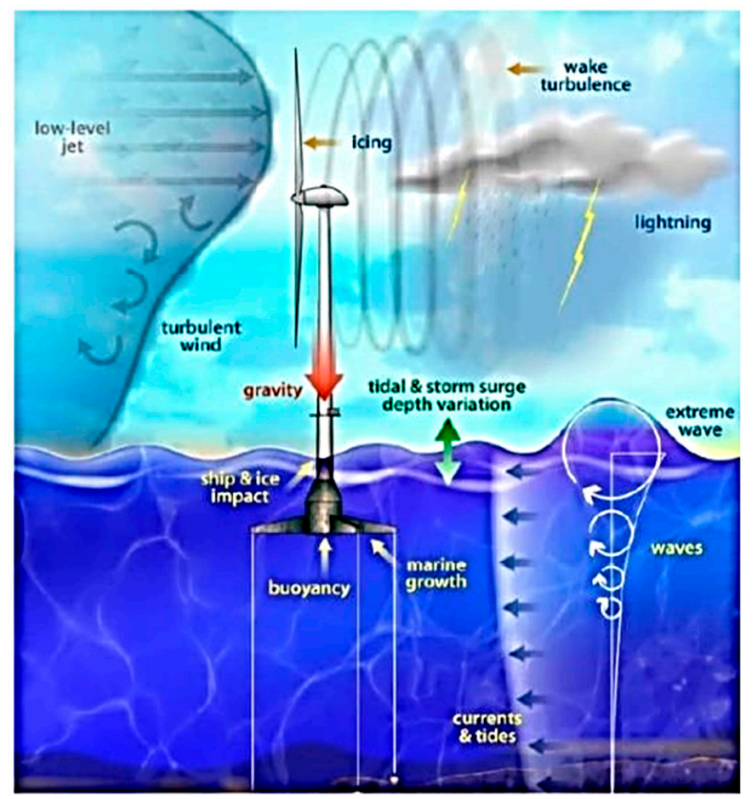

Figure 4. Types of wind and wave loadings on an FOWT [37].

\subsection{Excitation of Foundation Platforms}

Understanding the effects of wave loading on floating foundations of offshore wind turbines is important as it has large implications on angles-of-attack formed by rotating blades with the on-coming wind. This affects the formation and shedding of coherent flow structures, which determine the aerodynamic performance of turbines and their power generating capacity. The six degrees-of-freedoms (DOFs) associated with a floating offshore wind turbine include three translational DOFs representing heave (vertical), surge (along the central axis of the rotor) and sway motions. The three rotational DOFs are yaw (around the central axis of the tower), roll (around the central axis of the rotor) and pitch motions. Wave loads or hydrodynamic excitation on floating structures can represent regular as well as irregular sea states. These interactions of waves can cause surge, pitch, yaw or roll motion for the base platforms. Both vertical-axis wind turbines (VAWTs) and horizontalaxis wind turbines (HAWTs) are designed with floating platforms. VAWTs require simpler blade geometries and have better stability with floating platforms, which mitigates the development of fatigue loads in blades [16,17].

A usual phenomenon in wind turbine aerodynamics is the experience of yawed flows by turbines, where the wind encounters the blades making an angle with the rotor axis. Wen et al. [38] performed numerical simulations to determine the effects of static and dynamic yaw motion on the angles-of-attack $(\alpha)$ of blades by using free-vortex method, based on potential flow theory. It was determined that variations in $\alpha$ were associated with three 
different phenomena: the blade advancing and retreating effect, the non-uniform induction effect and the upwind and downwind yawing effect. Different mathematical terms in the definition of $\alpha$ are used under different flow and kinematic conditions to attribute changes in $\alpha$ with these three phenomena. The first one explains a situation, where a blade is first advancing, and then, retreating from the vortex wake. The second one belongs to the quantification of axial induction factor, which shows reduction in wind velocity from free-stream value near the rotor. The last phenomenon relates to the yawing motion of the platform to align the rotor with the in-coming wind. Bounds on positive and negative $\alpha$ have also been explained due to these phenomena under static and dynamic yawing conditions. The surge motion has the potential to significantly affect the wake of a FOWT by stretching and compressing three-dimensional vortex structures. Having different length scales, vortices are shed from the rotating blades and other components, such as nacelle and tower. The moving offshore platform can lead rotors to move forward and backward, causing propeller-like conditions or vortex-ring states [14]. Lei et al. [16] used a CFD solver STAR-CCM+ with the improved delayed detached eddy simulation (IDDES) using overset meshing technique for a 3-bladed vertical-axis wind turbine with its foundation undergoing a periodic surge motion. They determined that variations in surging amplitudes caused maximum torque appearing in different intervals of a period, which has a direct influence on fatigue loads over blades. This surge motion of the foundation can significantly affect the aerodynamics of turbines. Smaller amplitudes with smaller surging frequencies not only mitigates oscillations in aerodynamic forces and unbalancing moments, but it also helps keep turbines steady with higher power output. Their flow visualizations shown in Figure 5 depict that stronger large-sized flow structures are formed when a FOWT experiences surge motion of its base. Cormier et al. [26] used RANS-based numerical simulations to determine that specific relations between the surge motion and rotation of the blades would cause stable merging of vortices that further affect the turbine performance.

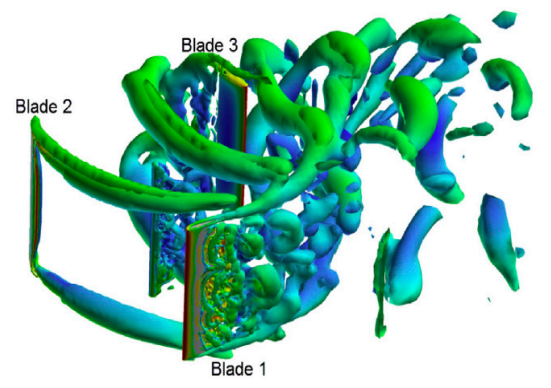

(a)

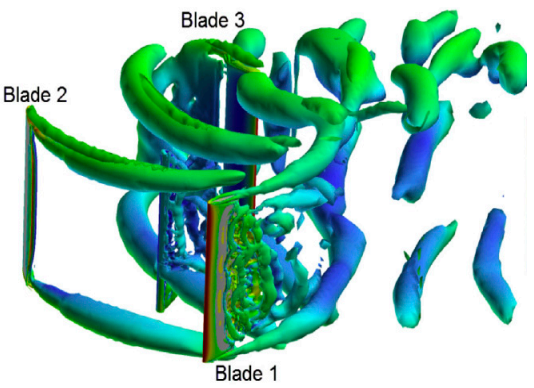

(b)

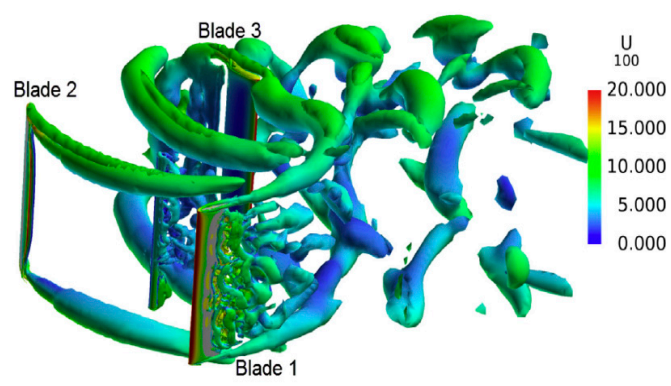

(c)

Figure 5. Coherent structures around an offshore vertical-axis wind turbine at (a) mean surge position, (b) maximum surge displacement and (c) no surge motion (Adapted with permission from ref. [16]. Copyright 2017 Energy).

Lei [18] reported the formation of spindle-type wake structures, expanding in the downstream direction for a floating vertical-axis wind turbine undergoing surging motion. This phenomenon becomes more pronounced for increasing surging periods and amplitudes. Shen et al. [39] demonstrates that for a $5 \mathrm{MW}$ floating offshore wind turbine, certain kinematic parameters of its surging motion can improve the power generation by more than $3 \%$ in comparison to that produced by onshore turbines under the same wind conditions. They employed an unsteady lifting surface method integrated with a free-wake model to show that the attached flows with blades would keep turbines stable under surging loads. This can be destabilized with the blades experiencing stall. Liu et al. [13] further introduced aeroelastic models, using the beam theory, to enable two-way fluid-structure interactions around the turbine blades. The results show that utilizing flexible blades reduce aerodynamic performance parameters, including thrust and power, by $5 \%$. This is due to a nose-down twisting maneuver that results in reducing respective $\alpha$. Their findings 
also showed that the surge motion coupled with aeroelastic rotating blades can introduce a lag between temporal profiles of aerodynamic loads and the prescribed kinematics of the turbine. The production of negative thrust has also been observed by Kyle et al. [14], leading to the emergence of a propeller-like condition, for wind speeds of $7 \mathrm{~m} / \mathrm{s}$ and 11 $\mathrm{m} / \mathrm{s}$, and surging motion with an amplitude of $9.4 \mathrm{~m}$ and a frequency of $0.12 \mathrm{~Hz}$. The blades experience lower $\alpha$ under such conditions due to a small relative velocity at the rotor, which further leads to negative lift generation. Under the other vortex-ring state, coherent flow structures on the tip and root of a blade recirculate around the blades, causing flow detachment. It mitigates their shedding in the wake. The occurrence of vortex ring states has also been examined by Dong and Vire [40] for numerous flow and kinematic conditions. A particular conclusion centers around uncovering the correlation between this phenomenon and minimum relative velocity of wind perpendicular to the turbine rotor.

Stand-alone pitching motion has substantial impact on the aerodynamic forces and moments experienced by floating wind turbines. Their performance parameters are sensitive to variations in pitching amplitude and frequency [17]. Lei et al. [17] used STAR-CCM+ with the improved delayed detached eddy simulation (IDDES) using overset mesh technique for a 2-bladed offshore floating vertical-axis wind turbine with its base undergoing pitching motion. The periods of pitching motion are considered as integral multiples of the blades' rotational periods. It has been observed that the turbine experiences more torque at maximum pitching amplitudes compared to that at no pitching states. Blade tip vortices are more coherent for pitching conditions than those with no pitching motion. However, an oscillating base also causes more intense interactions between blade-tip vortices. The induced velocity due to the pitching platform affects the relative speed between blades and in-coming wind. It consequently influences the aerodynamic parameters. In this scenario, another key factor is increasing sweep area of the turbine rotor. Another study by Lei et al. [18] reveals that some pitching motion profiles can cause expansion of momentum-deficit regions in the wake. However, a clearer trend for its dependence on pitching amplitudes and frequencies cannot be determined properly. Wen et al. [41] introduced two other governing parameters, tip speed ratio $(\mathrm{TSR} ; \lambda)$ and reduced frequency $(\omega)$, in their investigations, which have been defined as:

$$
\begin{gathered}
\lambda=\frac{\Omega R}{U_{\infty}} \\
k=\frac{\omega \beta_{\circ} H}{U_{\infty}}
\end{gathered}
$$

where $\Omega$ is the angular velocity of rotor, $R$ is its radius, $U_{\infty}$ is the in-coming wind velocity, $\beta_{\mathrm{o}}$ is the maximum pitch angle, $\mathrm{H}$ is the tower height and $\mathrm{k}$ represents a correlation between oscillation frequency and amplitude. The latter parameter also has certain significance in offshore environments, as turbulent sea states involve large $\beta_{\mathrm{o}}$ and lower $\omega$ [42]. They found that the time-averaged power $\left(\overline{\mathrm{C}_{\mathrm{P}}}\right)$ has a direct relationship with $\mathrm{k}$. For lower $\lambda, \overline{\mathrm{C}_{\mathrm{P}}}$ decreases with an increasing $\mathrm{k}$, whereas $\overline{\mathrm{C}_{\mathrm{P}}}$ decreases under such conditions for higher $\lambda$. Higher fluctuations, which are detrimental for the structural integrity of a wind turbine, were computed for increase in both these parameters. Fang et al. [32] examined the impact of pitching kinematic parameters on the performance of a floating offshore wind turbine. It has been reported that a decreasing pitching frequency results in lower amplitudes of rotor's torque and thrust, whereas these amplitude exhibit increase with an increasing $\beta_{\mathrm{o}}$. Interference of large-scale coherent flow structures have been observed when the pitching frequency is large with a high $\beta_{\mathrm{o}}$. Large values of $\beta_{\mathrm{o}}$ also make the rotor experience stall, which deteriorates its aerodynamic performance. Moreover, Shi et al. [15] has reported that temporal thrust profiles are synchronized with incident waves. Thus, thrust increases when low-frequency wave encounters the turbine. This trend becomes more significant for higher wind speeds.

Fully coupled computational solvers integrating wind, wave and structural dynamics propose the most accurate numerical tools for investigating FOWTs. There are a few 
studies in recent literature where excitations in multi-DOFs for foundations of FOWTs have been considered [10,19,25,29,43-47]. Liu et al. [19] has developed this type of solver using OpenFOAM, an opensource CFD tool, using arbitrary mesh interface (AMI), which is essentially a sliding mesh technique. 3DOF, including surge, heave and pitch, with prescribed kinematic profiles have been employed. The accuracy of this framework has been validated against a 5 MW FOWT developed by the National Renewable Energy Laboratory [48] and OC4 DeepCWind semi-submersible FOWT [49]. Volume-of-fluid (VoF) method has been utilized to capture the air-water interface and the formation of free surfaces. The following models have been introduced in the solver to define wave conditions at the inlet boundary:

$$
\begin{gathered}
\text { Linear wave model }: \eta=A \cos \theta \\
\text { Horizontal velocity profile }: \mathrm{u}=\frac{\pi \mathrm{H}}{\mathrm{T}} \frac{\cosh \mathrm{k}(\mathrm{z}+\mathrm{d})}{\sinh \mathrm{kd}} \cos \theta \\
\text { Vertical velocity profile }: \mathrm{v}=\frac{\pi \mathrm{H}}{\mathrm{T}} \frac{\sinh \mathrm{k}(\mathrm{z}+\mathrm{d})}{\sinh \mathrm{kd}} \sin \theta
\end{gathered}
$$

In these models, $\mathrm{A}$ and $\theta$ denote amplitude and phase of the wave, respectively. Moreover, $\theta=\mathrm{kx}-\omega \mathrm{t}$ with $\mathrm{k}$ and $\omega$ being the wave number and circular wave frequency, respectively. Additionally, $\mathrm{H}=2 \mathrm{~A}$ stands for the wave height and $\mathrm{d}$ is the depth of water. An important concern in computational modeling of these problems involves handling the reflection of waves from the outlet boundary. This was achieved by introducing a sponge layer near the outlet boundary by adding a source term in the Navier-Stokes equation for momentum balance. This source term contains an artificial viscosity term as a damper in the virtual environment. Figure 6 depicts the coherent flow structures formed due to rotating blades, tower, and the nacelle of the turbine. However, how these vortices influence aerodynamic forces and moments, and contribute to stabilize the floating structure, are still unknown. The extraction of these complex flow features and uncovering their relations to instantaneous performance metrics are crucial to the design of high-performance FOWTs. A similar turbine and floater model has been employed by Tran and Kim [26] for the numerical analysis using the overset grid method and a quasi-static model for loads on mooring cables. Furthermore, Lienard et al. [50] reported that out of all the DOFs, pitch and surge motions of foundations have more influence on the performance of wind turbines.

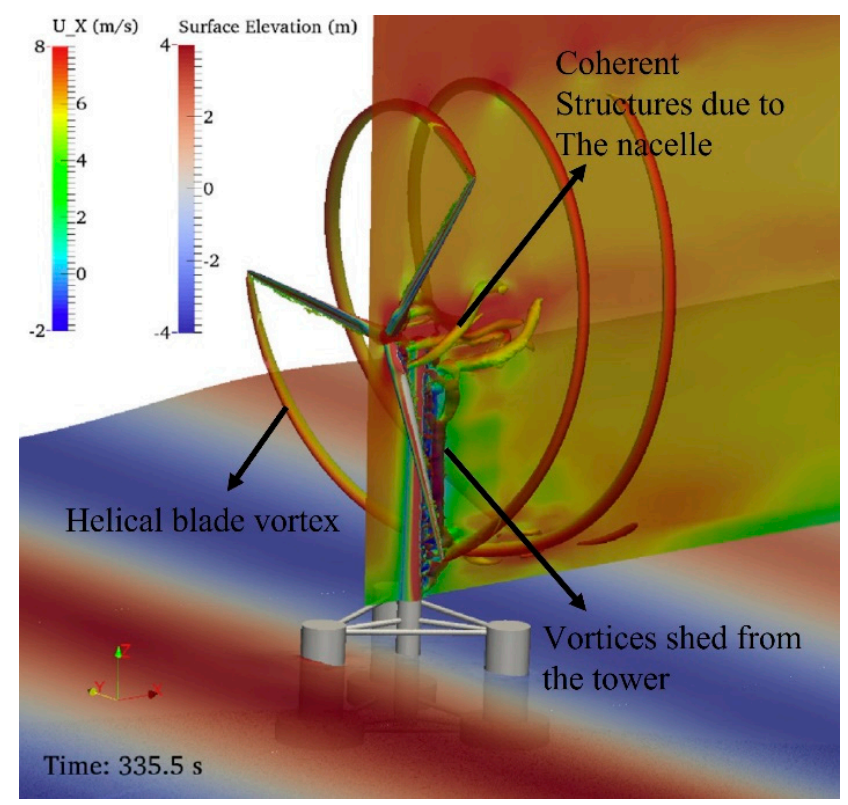

Figure 6. Coherent structures around a floating offshore wind turbine [19]. 
The aforementioned discussions exhibit that our knowledge about important flow features that dictate the performance of floating offshore wind turbines is far less than required to substantially accelerate their design and development. Extensive investigations are required to examine how complex coherent structures are formed by rotating blades, nacelle, tower and platform under different flow and kinematic conditions. The existing studies identify that their strong interactions with each other greatly influence the power produced by these turbines. In addition to time domain modeling techniques, frequency domainbased methods and transfer function approach are also employed by several researchers to introduce a wide spectra of irregular waves in computational modeling of hydrodynamic loads and dynamic response of offshore wind turbines [51-56]. The linear frequency domain technique neglects the key effects related to inherent nonlinear rigid-body and flow dynamics of floating structures and the coupled aerodynamics-hydrodynamic performance of floating offshore wind turbines [10,52].

Another important aspect of offshore energy harvesting structures is the influence on their performance and dynamics by ice sliding around them and ice accretion on the rotating blades. These phenomena can adversely affect the power generation capacity from their blades, but also substantially enhance dynamic loads on towers and resultant motion of their foundations. A detailed review including the effects of icing on modeling procedures for wind turbines was recently presented by Martini et al. [57]. Besides, Ye et al. [58] considered various scenarios in their numerical simulations, including damp air, humidity, water condensation and icing on the blades of an offshore turbine. Their results hinted that thin films developed over blades due to condensation of water did not influence the aerodynamics or power generation of the turbine. However, icing and foggy weather were identified as critical factors, the impact of which need to be included in the estimation of performance metrics. In another study, a simple model using two different positions of rotating blades was employed by Lagdani et al. [59] to examine and compare clean and iced profiles of blades with NACA4412 cross-sections. They linked the degradation in the performance of the turbine with accumulation of ice on the leading edge of a blade. Primarily, these studies only focused on stationary states of blades, which portray simplistic approaches to handle complex phenomena. Hence, more accurate computational models and algorithms need to be developed to handle icing and weather conditions around the blades of offshore turbines.

\subsection{Numerical Modeling for Control Design}

Controlling wind turbines in offshore farms is used to improve their aerodynamic performance, power generation and coordination with other turbines in the farm. Control techniques are devised to make interactions of turbines and their wakes more productive. Quite interestingly, wakes of wind turbines are deflected [60] and those present in the downstream direction should not directly interact with the momentum-deficit regions in the wakes of upstream turbines. For this purpose, yaw-based wake steering technique is employed to enhance the net power generation of turbines placed in arrays [61]. Fleming et al. [62] developed a wind farm controller to carry out wake steering and implemented it over a commercial offshore wind farm in China by partnering with Envision turbines, a company for manufacturing turbines. Owing to their simpler formulations and low computational cost, low-order aerodynamic/hydrodynamic models are vastly used in designing controllers for large structures. For instance, Chen et al. [21] employed bladeelement momentum theory and strip theory with second-order wave forces and Morison's equation for computing aerodynamic and hydrodynamic loads. The dynamic response of the structures was handled by Kane's equations with different methods, including adjacent array approach, hybrid coordinate dynamic analysis and Cardan angles method. The developed controllers tackled generator torque and pitch angle of the blades. Furthermore, Sang et al. [63] developed cyclic and collective pitch controllers for a two-bladed floating turbine utilizing FAST solver. It has been concluded that using such control strategies can help reduce loadings on floating offshore wind turbines. 


\subsection{Offshore Wind Turbine Farms}

Installing wind turbines in the form of clusters and farms can significantly increase their performance; downstream turbines can extract energy from the vortical flows shed by their upstream counterparts [64,65]. Additionally, direct interactions of velocity-deficit regions in the wake of an upstream turbine with the rotating blades of a downstream one degrades its performance [8]. Hence, it demands special care of setting the spaces between floating offshore wind turbines when they are arranged in arrays [66]. Due to the allied cost and complexity for replicating wind and wave conditions in controlled laboratory environments, computational techniques are favored for studying these effects and their consequences. Though virtual in nature, they provide considerable flexibility to introduce variations in the governing parameters and changing array configurations of turbines. Hence, the most recent advancements in this field rely on numerical simulations to determine the aerodynamic performance of offshore wind farms. However, the associated computational cost is enormous due to the multi-physical nature of these systems and mesh requirements to solve governing mathematical models. Gargallo-Peiró et al. [30] proposed a new mesh generation technique for offshore wind farms, modeling turbines as actuator disks in atmospheric boundary layer. It involves automatic hybrid conformal grid generation processes with improved resolution in between different turbines to resolve wake features. It has not been explained in the study how the algorithm will address (or be extended to tackle) the multi-component flows with air-water interface and loads simultaneously applied by both wind and water on turbine rotors. Naderi et al. [27] developed steady-state computational models of wind farms based on actuator disks coupled with numerical schemes of computational fluid dynamics in OpenFOAM. Figure 7 presents velocity variations in a wind farm, depicting the extent of wake recovery for different angles of the incoming wind. This indicates that turbines in the downstream rows may avoid encountering disturbed wind profiles and in a better position to enhance their power production. Depending on the turbulence intensity, wake can recover its kinetic energy and help turbines in rear rows improve their performance.
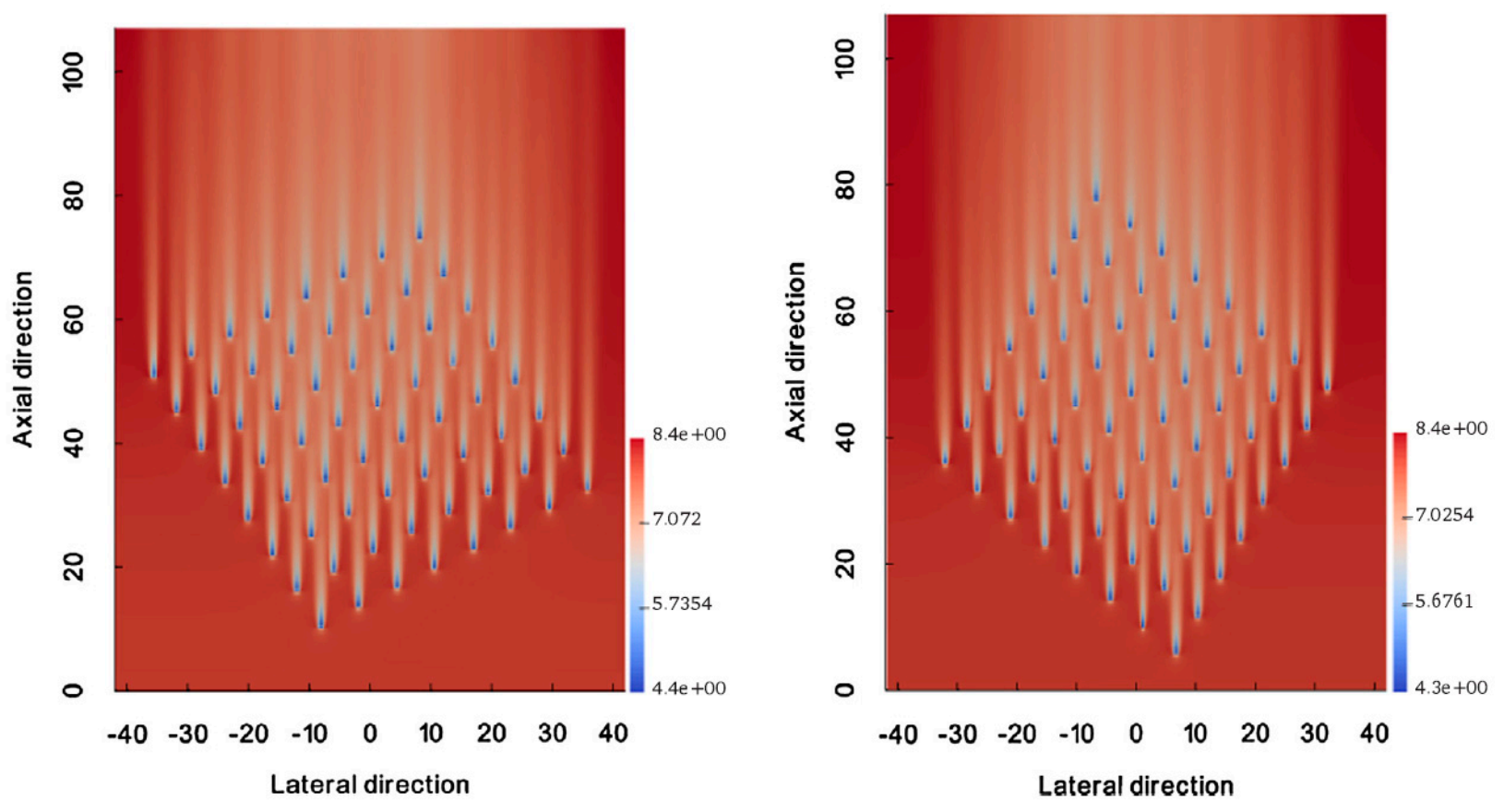

Figure 7. Velocity variations around two different arrangements of offshore wind turbines farms (Adapted with permission from ref. [27]. Copyright 2018 Energy Conversion and Management).

A similar approach by Richmond et al. [28] showed that actuator disk models are effective for simulating wind farms. It has been observed that there are inconsistent error trends 
in different parameters, which highlights the need for better numerical methods. Rezaeiha and Micallef [24] have also adopted the same approach to investigate the performance of two floating offshore wind turbines in tandem. The foundation of the upstream turbine has been excited with a surge motion profile, whereas the one in the downstream direction has been kept fixed. It has been demonstrated that the surge motion causes enhancement of the power output for both turbines. This oscillating motion of the leading turbine causes the mixing of vortices, which further help wake recovery. Another approach is to couple the actuator line method within CFD solver packages, such as OpenFOAM, which has been followed by Wang et al. [67]. Numerical investigations for parametric variations show that carefully controlling the incoming wind angle can help optimize the overall power produced by the wind farm. Although they incorporated different yaw and tilt angles of turbines, the impact of temporal wave profiles on the overall metrics remains unclear. Multi-unit forums equipped with multiple wind turbines are also becoming popular for offshore energy harvesting [18,26]. However, our knowledge on the effects of coupled wave loads and the resultant wake interactions, dictating the performance of these energy harnessing machines, is very limited.

\subsection{Flow Induced Acoustics}

When solid structures undergo motion in a fluid, pressure waves are generated in their surroundings, propagating acoustic signals. These features can cause noise pollution in aquatic environments and disturb the natural habitats of marine species. Due to the construction of large farms of floating offshore wind turbines in oceans, migration routes of aquatic animals can be changed, which would have an adverse impact on underwater ecosystems. It is therefore important to quantify flow-induced sound emitted due to operations of these floating structures. Offshore wind turbines also reduce the sensitivity of seismic stations to measure the low-frequency motion signals in ocean beds due to earthquakes or testing of mass-scale weapons. Moreover, mixed seismic signals are produced by the support structures and mooring cables. Thus, it is important to examine the emitted flow-induced aero-acoustic signals. Klein et al. [68] developed a computational model for fluid-structure-acoustic coupling of a $5 \mathrm{MW}$ wind turbine to ascertain that the blade-passing frequency is the dominant harmonic component in aero-acoustic spectra. Structural eigenfrequencies of the tower further add to the complexity of sound signals. It has been concluded that the tower is a more dominant acoustic source as a result of the blade-tower interactions with the passing wind, where turbulence intensity is $16 \%$. An example of the impacts of large offshore wind turbines on the environment include reported incidents of dead birds around wind farms. In such cases, motion smear is the factor that can be very harmful for birds flying over oceans for intercontinental migration. May et al. [69] have reported that the fast-moving rotors of offshore wind turbines can appear blurry to the birds, causing collisions, resulting in the death of many bird species. When one blade was painted black, it reduced bird deaths by $70 \%$. These collisions also cause damages to turbine structure, thus degrading their aerodynamic performance. Thus, more extensive efforts are required to understand how flow-induced acoustic signals from offshore wind turbines impact the lives of biological species. Evaluating the impact of governing kinematic parameters of wave loading, turbulence intensity and tip-speed ratio is required to come up with more effective designs of offshore wind turbines. Simultaneously, detailed knowledge on fluid-structure-acoustic interactions should be obtained, so that effective flow control strategies can be designed and implemented. A significant gap in our current knowledge relates to the emission and propagation of acoustic signals when multiple offshore wind turbines operate in close proximity of one another.

\section{Structural Integrity of Offshore Wind Turbines}

The structural integrity of offshore wind turbines plays a vital role in deciding the commercial viability of these structures. Recent research investigations employ a range of different analytical, empirical and numerical methods to evaluate the structural integrity 
of offshore wind turbines. Structural integrity of innovative offshore turbine technologies is an integral part of technology readiness level (TRL) 6, i.e., technology demonstration. Structural integrity analyses of the various offshore wind turbine components are crucial for the evaluation of stresses and the resulting strains that offshore wind turbines have to bear under wide ranging weather conditions. This leads to the development of more accurate models for estimation of remaining useful life (RUL) of offshore wind turbines. This section of the study provides a review of recent scientific advancements regarding the structural integrity of offshore wind turbine, with special attention to the blades, the subsea support structure and the tower.

\subsection{Wind Turbine Blades}

Boudounit et al. [70] have carried out numerical investigations on the structural integrity of wind turbine blades under in-service and off-service wind conditions. Finite element models of two different wind turbine blades, one made of fiberglass/epoxy composite and the other made of carbon fiber/epoxy composite, have been created as shell elements in the numerical environment. The length of both blades was $48 \mathrm{~m}$, weighing $12.18 \mathrm{t}$ for fiberglass/epoxy and $9.54 \mathrm{t}$ for carbon fiber/epoxy. The aerodynamic design of the blades considered was NACA4424 with a maximum camber of $4-14 \%$ from the leading edge and a maximum thickness of $24 \%$. Encastre type constraints have been applied at the blade root, while all three aerodynamic gravity and centrifugal wind loads have been incorporated into the model (in-service at $25 \mathrm{~m} / \mathrm{s}$ and off-service at $75 \mathrm{~m} / \mathrm{s}$ ). Hashin's criteria for damage initiation in composite materials (firer and matrix failure modes, i.e., fiber tension/compression and matrix tension/compression) have been used to analyze the structural integrity of the blades [71,72]. The numerically predicted results indicate that the blade tip displacement in case of fiberglass/epoxy composite blades is significantly higher than carbon fiber/epoxy blades; under off-service conditions, it can be 2.2 times more. Hashin's criteria has been met by the fiberglass/epoxy composite blade at $55 \mathrm{~m} / \mathrm{s}$ wind speed, leading to matrix cracking followed by fiber-matrix interface violation and eventually fiber failure. The stiffness of carbon fiber/epoxy blades has been recorded to be 3.7 times higher than fiberglass/epoxy blades, making them a more suitable material for wind turbine blades manufacture. Hand et al. [73] carried out extensive finite element analysis (FEA) on a $5 \mathrm{MW}$ offshore wind turbine blades made of glass fiber reinforced polymer. Structural analyses have been carried out at most critical wind load cases as defined in IEC 61400-01 Class 1A [74], for example at $70 \mathrm{~m} / \mathrm{s}$. Longitudinal strain has been analyzed along the spanwise direction of the blades. The numerical results obtained show compressive strain on the camber face of the blade, at the blade mid-span, with values of the longitudinal strain well within the allowable limits. This has been compared against the results from an analytical model, which assumes the blade as a beam with all the parts lumped together. It has been computed that the analytically calculated longitudinal strain on a blade is $8.7 \%$ higher. The maximum flapwise deflection at the blade mid-span has been numerically predicted to be $2.9 \mathrm{~m}$ under critical wind load conditions. The study also states some recommendations for future work, which include analysis of blade fatigue resulting from varying azimuthal angle (and hence, varying aerodynamic loads), fluid-structure interaction-based studies, etc.

Finnegan et al. [75] experimentally investigated a full-scale $(13 \mathrm{~m})$ wind turbine blade under dynamic and static loading conditions. Flapwise and edgewise testing has been carried out in order to evaluate the structural response of the wind turbine blade. Experimental data have been recorded using electrical resistance strain gauges, linear variable differential transformer, 3D laser scanner, vibrometer, load cells, accelerometers and a digital image correlation system. The empirical results obtained depict non-linear distribution of flapwise and edgewise loads, for different loading conditions considered (i.e., maximum, 75\%, 50\% and 25\%). Numerical techniques have been used from different commercial solvers analyzing the blade deflection and strain. It has been observed that ANSYS is more accurate in predicting the natural frequencies of the blade, while CalculiX 
better estimates the blade deflection, both flapwise and edgewise. It has been further noticed that both ANSYS and ABAQUS underestimate blade edgewise stiffness, while all three solvers underpredicted the blade strain. Finnegan et al. [76] further developed this work through the inclusion of a blade leading edge protective layer made of thermoplastic polyurethane. The protective coating has been applied to the blade in order to minimize the effects of erosion from rain droplets [77]. The turbine blade is subjected to static tests where the loading is applied at different points along the length of the blade. A numerical model has also been developed for the scaled turbine blade and the numerical predictions regarding blade deflection have been validated against the static test results. An enhanced numerical model has also been developed with a full-scale $13 \mathrm{~m}$ long blade of a $225 \mathrm{~kW}$ turbine. A blade tip deflection of $\sim 550 \mathrm{~mm}$ has been recorded, with a maximum von Mises stress of $200 \mathrm{MPa}$ along the spar caps. This is significantly lower than the allowable stress of $643 \mathrm{MPa}$. The numerically predicted results have been compared against the experimental data obtained by Fagan et al. [78] for the same blade, which shows blade tip deflection of $700 \mathrm{~mm}$, demonstrating that the inclusion of the blade protector increases the stiffness of the blade. It has been further noticed that in a concentrated area at the blade tip, the stresses (von Mises, frictional and tensile) are higher than the yield strength of the material, which will need to be addressed.

Navadeh et al. [79] numerically investigated a composite rotor blade with a stiffener, represented as a shell-type model. The study focuses on the linear perturbation analysis of the blade with different stiffener thicknesses. Vibration analysis of the blade depict flap character, lead-lag and flap with lead-lag for the various modes. Based on geometric non-linearities and employing a linear elastic model, blade tip displacements have been computed, demonstrating that for lower pressure values, the non-linearity in the displacement is negligibly small. Numerically predicted results show a significant increase in the reaction forces where the stiffener is attached to the blade. Two severe loading conditions have also been investigated, i.e., a pulse load mimicking a sudden impact and half-sine load mimicking wind gust. It has been observed that geometric non-linearities increase flap deflection of the blade, increase time shift in blade tip displacements and excitation of longitudinal vibrations. Ali et al. [80] studied the dynamic response of wind turbine blades in order to develop a genetic algorithm-based optimization model, under seismic conditions. Contribution of web stiffness and torsional stiffness for unstiffened and stiffened blades have been estimated. For case study, a $5 \mathrm{MW}, 61.5 \mathrm{~m}$ long blade has been considered. Optimization has been carried out for an objective function defined for minimum difference between the dynamic response of the blade obtained from the model developed and the experimental results [48]. The range of design variables considered comprises of $15 \mathrm{~mm}<$ blade thickness $>35 \mathrm{~mm}, 1220 \mathrm{~kg} / \mathrm{m}^{3}<$ material density $>1920 \mathrm{~kg} / \mathrm{m}^{3}$, $2<$ shear modulus $>12$ and $40<$ young's modulus $>115$. For the different blade configurations, the optimization algorithm predicts similar frequencies. The anisotropy in the blade material leads to higher flapwise and edgewise stiffness near the root. A modal analysis carried out revealed that there are several higher modes in the blades, which are non-existent in the conventional approach used for model analysis of turbine blades, i.e., lumped mass approach.

\subsection{Offshore Wind Turbine Substructure}

As mentioned in the introduction section, the main difference between onshore and offshore wind turbines is the way they are supported and thus, substructures are an integral part of offshore turbines. A significant number of recent scientific investigations have been carried out on fixed support type offshore wind turbines, while very few studies are publicly available on floating offshore wind turbines. It is, however, noteworthy that the future of offshore wind turbine technology lies with the floating offshore wind turbines as their rated power can be significantly higher than fixed support offshore turbines, potentially making them more cost per kWh effective. 
Oh and Ishihara [81] carried out a full-scale structural analysis of a 2.4 MW offshore wind turbine with a gravity support structure. The empirical investigations have been carried out through excitation testing of an active mass damper, analyzing the damping ratios for different frequency modes. Sinusoidal vibration and free decay testing criteria have been employed for estimating the structural mechanics of the wind turbine. Results show that the damping ratios during sinusoidal vibration testing are $0.2 \%$ for the first mode and $2.4 \%$ for the second mode. For free decay testing, the fore-aft modes are similar to the sinusoidal vibration testing. However, side-side modes result in damping ratios of $1.2 \%$ and $3.2 \%$, respectively, for the first and second modes. An empirical model has been developed to estimate the damping ratio for the first mode. This work has been expanded further by Ishihara and Wang [82] to induce the effects of soil properties using genetic algorithm (GA). Numerical investigations have been carried out on gravity support and monopile support structures, and the modal results validated against field data. It has been observed that the damping ratio is strongly dependent on the soil stiffness. The increase in damping ratio for the second mode of gravity support structure is due to the riprap layer, which is softer than the original soil. For the monopile support structure, soil stiffness affects both modes. Gentils et al. [83] have carried out numerical investigations on the structural mechanics and optimal design of offshore wind turbine support structures. Finite element analysis (FEA) has been coupled with GA (integrated optimization) with the objective of minimizing the weight of the monopile support. The optimization criteria employed are the standard requirements of vibrations, stress, deformation, buckling, fatigue and design constraints. The integrated optimization model has been applied to $5 \mathrm{MW}$ turbine from the National Renewable Energy Laboratory [48]. Numerical predictions for the aero-hydroelastic analyses have been validated against the reference offshore wind turbine data. The design variables considered for the natural selection GA are the outer diameter and the thickness of the multi-component subsea support structure. The optimal structural design obtained demonstrate a mass saving of $19.8 \%$ with the structural parameters within the allowable limits, as summarized in Table 2.

Table 2. Structural behavior of the optimized support structure [83].

\begin{tabular}{lcc}
\hline \multicolumn{1}{c}{ Parameter } & Value & Allowable Limit \\
\hline 1st Modal frequency & $0.2123 \mathrm{~Hz}$ & $0.212-0.328 \mathrm{~Hz}$ \\
Von Mises stress & $288 \mathrm{MPa}$ & $<323 \mathrm{MPa}$ \\
Tresca stress & $24 \mathrm{MPa}$ & $<67 \mathrm{MPa}$ \\
Deformation & $0.078 \mathrm{~m}$ & $<0.1 \mathrm{~m}$ \\
Rotation & $0.342^{\circ}$ & $<0.4^{\circ}$ \\
Fatigue safety ratio & 1.2 & $>1.15$ \\
Buckling load multiplier & 1.7 & $>1.4$ \\
\hline
\end{tabular}

Ram and Mohana [84] carried out FEA of a conventional monopile substructure with the aim to find out the variations in stresses, deformation and strain energy, under realistic operating conditions. The substructure analyzed has a height of $30 \mathrm{~m}$ and a diameter of $5 \mathrm{~m}$, attached to $78 \mathrm{~m}$ high tower through an $18 \mathrm{~m}$ long transition piece. The operating parameters considered includes: (i) soil density, cohesion, friction angle and depth; (ii) structural steel's mechanical properties; (iii) IEC Class IA wind class turbine with a power rating of $3 \mathrm{MW}$; and (iv) wave loads based on linear Airy wave theory and wheeler stretching method using Morison's equation. However, the investigations are limited to short-term static loading conditions only. The numerically predicted results indicate that maximum deformation, principal stress and elastic strain all occur at the tower head, ensuring that the monopile's structural integrity falls within the serviceability requirements [85]. It is stated that the strain energy is dissipated to water and soil. Analysis of the blade passing frequency, rotational frequency and wave water frequency all show that the monopile substructure avoids resonance effects. Luengo et al. [86] carried out parametric investigations on the structural integrity and capital expenditure of offshore 
wind turbines. Effects of (i) length of transition piece and grouted connection, (ii) size and number of transition piece stoppers and (iii) scour development have been investigated using FEA. The various loads considered on a 3.6 MW Siemens turbine with an $80 \mathrm{~m}$ heigh tower and $31 \mathrm{~m}$ deep monopile structure, include IEC 61400-01 Class 1A wind loading, wave loading (Morison's equation), tidal loading, hydrostatic pressure and the weight of the nacelle-rotor assembly (RNA). Numerically predicted results have been validated against the field data. It has been observed that $\pm 1 \mathrm{~m}$ variation in the length of the transition piece and/or the grouted connection has an insignificant impact on the structural behavior of the offshore wind turbine, while a mass saving of $20 \mathrm{t}$ is possible. Increasing the number of stoppers has a beneficial impact on the structural behavior of the offshore wind turbine. However, more stoppers mean higher costs. It has been further noticed that frequency modes 2 and 4 are especially impacted by the scouring of the foundation. Integrity monitoring of scouring has been proposed to be a better alternative to conventional scour monitoring techniques.

Ma et al. [87] numerically investigated the effects of scour on the structural integrity of tripod support structure for different wave loadings. 3D FEA has been carried out on a $6 \mathrm{MW}$ offshore wind turbine from the National Basic Research Program of China [88], which has a tower height of $100 \mathrm{~m}$ and blade length of $80.35 \mathrm{~m}$. Previous FEA investigations carried in Stahlmann's research thesis [89], and the field data obtained by German Federal Maritime and Hydrographic Agency [90], indicate scour patterns in tripod foundations that are significantly different from monopile foundations and thus, have been used for FEA modelling. Wind, wave tidal and fatigue loads have been computed and considered in the numerical model. FEA has been carried out under (i) ultimate limit, (ii) serviceability limit and (iii) fatigue limit states and the numerical predictions validated against field data. It has been noticed that foundation scouring has minimal effects on the natural frequency of the tripod. Under ultimate limit state, the effects of scouring are significant on both the magnitude and location of von Mises stresses acting on the piles of the tripod, as shown in Figure 8. Under serviceability limit state, the effects of scouring are minimal on the deflection and rotation of the tripod, which is significant on the deflection of the piles. Under fatigue limit state, scouring tends to decrease the fatigue life of the tripod foundation. Shittu et al. [91] conducted a structural reliability assessment of a $10 \mathrm{MW}$ offshore wind turbine, supported by a jacket foundation, in order to characterize and analyze pitting corrosion on the structure. A damage tolerance approach has been employed using FEA for modelling the growth of cracks initiated by the pitting corrosion, leading towards corrosion fatigue (long cracks). Numerically predicted results have been validated against the reference data [48]. Post-processing of the numerical data has been carried out using Artificial neural network surrogate modelling approach. The predicted reliability index suggests that the turbine life is 18 years, as opposed to the theoretically predicted life of 22 years.

Ghigo et al. [92] carried out a comprehensive study on the feasibility of different floating offshore wind turbine support structures, comprising of hydrostatic analysis, platform optimization, site selection (offshore Italian coast) cost analysis and development of wind farms. The floating structures considered are HyWind (spar buoy) [5], Windfloat (semi-submersible), Hexafloat (pendulum floater), Sea Flower (hexagon with six columns) and a new concept design (similar to Hexafloat; without columns). The primary assessment criterion for floating offshore wind turbines is its metacentric height [93], which is the distance between the center of gravity and metacenter of the floating structure. Its importance is paramount to the structural stability of floating platforms. The hydrostatic analysis carried out by Ghigo et al. [92] include parameters, such as gravitational and buoyancy forces, hydrostatic stiffness and maximum static pitch angle. The platform optimization has been carried out using GA for minimal weight and material cost. The different geometrical parameters considered for this purpose include platform diameter and height, ballast height and mass. Design constraints used have been summarized in Table 3. Analysis has 
been carried out for a $5 \mathrm{MW}$ and a $10 \mathrm{MW}$ turbine. The material cost analysis indicates HyWind and Hexafloat are superior structures compared to the others.

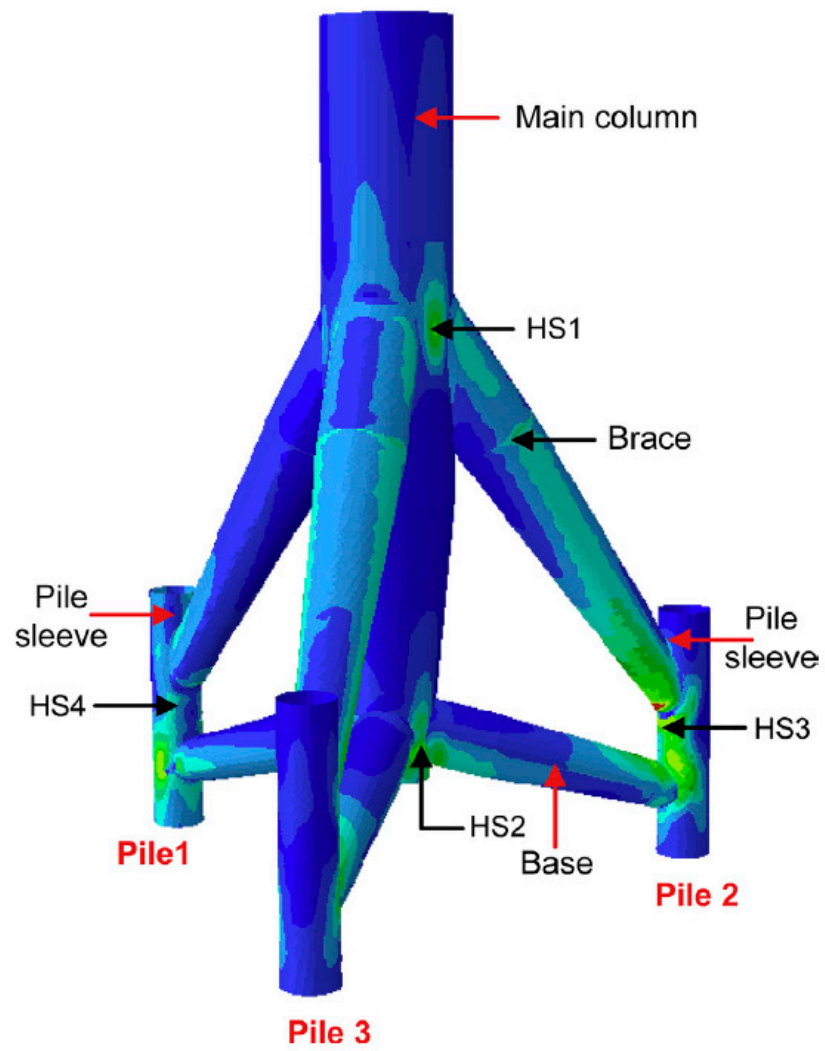

Figure 8. Severe fatigue locations on a tripod foundation (Adapted with permission from ref. [87]. Copyright 2018 Applied Ocean Research).

Table 3. Design constraints for the floating offshore platforms [92].

\begin{tabular}{lc}
\hline \multicolumn{1}{c}{ Design Parameter } & Stability Criteria \\
\hline Metacentre height & $>1 \mathrm{~m}$ \\
Draught & $>10 \mathrm{~m}$ \\
Freeboard height & $>5 \mathrm{~m}$ \\
Maximum static pitch angle & $<5^{\circ}$ \\
\hline
\end{tabular}

$\mathrm{Xu}$ et al. [94] have reported a comparative analysis of different mooring designs for shallow water $(50 \mathrm{~m}) 5 \mathrm{MW}$ floating offshore wind turbines with a view to find the optimal mooring design based on structural integrity and costs involved. Different catenary (chain) and taut (synthetic fiber rope) mooring cables, components (clump weight and buoy) and anchors (drag embedment and suction) have been considered for analysis. It is well established that mooring cable tension increases exponentially as the seabed depth increases [95], while its horizontal stiffness decreases, thus, a case study for $200 \mathrm{~m}$ depth has also been considered. Moreover, the non-linear response of taut mooring cables is dictated by the path of mooring cables and the duration of load exerted on them. An enhanced numerical model has been developed to account for these effects in taut mooring systems. The results obtained indicate that the inclusion of clump weight and buoys to fiber ropes is not significantly beneficial, while they are beneficial for traditional catenary mooring systems. The dynamic response suggests a hybrid catenary-taut mooring system can be more structurally stable and cost effective. Li et al. [96] developed a coupled dynamic response model and different tension leg mooring configurations analyzed using this model. Different operating conditions considered are regular sea state, extreme sea state and a broken mooring cable. The results indicate that the configuration with four tension legs and 
12 mooring cables with an inclination angle of $30^{\circ}$ is the most structurally stable mooring system, under extreme sea state as well. It has also been reported that when a mooring cable gets broken as a result of extreme loading (catastrophic event), this particular configuration of the mooring system still remains stable with negligible slack in the mooring cables.

\subsection{Wind Turbine Tower}

Dagli et al. [97] carried out a 2-way fluid-structure interaction (FSI) analyses on a variable geometry tower offshore wind turbine in order to analyze its dynamic behavior. The offshore shore wind turbine considered in this study resembles the fixed-support type. The effects of wind, wave and seismic loads on the stresses, displacements and natural frequency of the tower have been investigated. For wave loading, Morison's equation has been employed. Thus, only in-line wave motion has been considered. For the seismic effects, a cosine wave function has been used. Rayleigh's energy method has been used for single degree of freedom (SDOF) of the tower. The results obtained depict highest deformation at the top of the tower $(0.412 \mathrm{~m}$ from FSI and 0.382 from Rayleigh's energy method), while highest von Mises stress at its base $\left(1.16 \times 10^{10} \mathrm{~Pa}\right)$. Natural torsional frequencies have been computed using eigenvalue analysis with the first one at $9 \mathrm{~Hz}$. It has been advocated that Rayleigh's energy method is a close approximation of the coupled FSI modelling, and thus, it can be used as a precursor to high-fidelity numerical modelling. Asnaashari et al. [98] have numerically analyzed the frequency spectrum of an offshore wind turbine with a monopile foundation. Euler-Bernoulli beam element has been employed for carrying out FEA of the turbine tower and the transition piece. P-y method has been used to define the lateral interaction between the monopile foundation and the surrounding soil. Numerically predicted natural frequencies of the offshore wind turbine depict the first two bending modes at $0.35 \mathrm{~Hz}$ and $1.46 \mathrm{~Hz}$ for the Siemens $2.3 \mathrm{MW}$ turbine. In situ measurements have been carried out using low-frequency accelerometers at a sampling rate of $500 \mathrm{~Hz}$. Frequency response function (FRF) of the measured data show 1st and 2nd bending moments at $0.37 \mathrm{~Hz}$ and $1.7 \mathrm{~Hz}$.

A common simplification in modelling wind turbine towers using SDOF is to assume a concentrated mass at the top of the tower. As most wind turbine towers are tapered (variable geometry), this approach has a significant effect on the predicted turbine frequencies, resulting in calculation errors. Ko [99] has addressed this common problem while estimating the structural integrity of offshore wind turbines. The wind turbine and the operating conditions considered by Ko [99] are the same as studied by Dagli et al. [97], with the exception that Ko [99] also considers the flexibility in the foundation of the turbine. For this purpose, a concentrated spring model has been employed for structural modelling of the monopile and the transition piece. A closed-form solution of the natural frequencies of the offshore wind turbine has been developed and validated against experimental data. It is well known for wind turbines that the most common natural frequencies are $1 \mathrm{P}$ as the rotor frequency and $3 \mathrm{P}$ as the blade passing frequency. For accurate modelling of the wind turbine's cross-sectional moment of inertia distribution, a new equation has been derived, and the results have been compared with a $5 \mathrm{MW}$ turbine, showing better non-linear matching compared to conventional SDOF approach. The natural frequencies predictive by FAST and ADAMS solver for the NREL $5 \mathrm{MW}$ turbine are in close agreement with those calculated using the novel SDOF model. The seismic results are also verified. However, the additional damping in the fore-aft direction cannot be accurately captured using the novel SDOF model. It has been further noticed that the developed model shows promising results in estimating the natural frequency of the turbines affected by the foundation scour. Thus, it can be helpful in scour monitoring of offshore wind turbines.

Feliciano et al. [100] carried out numerical investigations on the effects of wind loading on the tower deflection, under realistic atmospheric stratifications. For this purpose, a large eddy simulation (LES) is conducted to predict the wind loads on a 5 MW NREL turbine farm. This data is then fed into a 3D FEA model in order to estimate tower displacement. The results indicate that as the wind turbulence increases, tower deflection also increases. 
The wind turbine rotor thrust has a significant impact on tower deflection, which is much more prominent than the effects of aerodynamic thrust. It has been noticed that stand-alone turbines are subjected to larger tower deflections compared to tower deflections in the wind turbine farm. A generic analytical model has been developed to estimate tower deflection. The analytical model is based on a simplified 2D cantilever beam and 1D momentum principle. The main advantage of this model is that its only input is the wind velocity. It has been demonstrated that the generic analytical model developed predicts tower deflections with reasonable accuracy. Kim et al. [101] carried out experimental investigations on fault detection in a scaled model of a wind turbine. Faults have been introduced at different locations of the tower. Frequency domain decomposition (FDD) has been carried out on the data recorded by the accelerometers along the length of the tower. FEA modelling of the wind turbine tower has been carried out as well, with the aim to compare the modal frequencies and mode shapes from the two techniques. The results indicate that damage in the near-bottom region of the tower has a significantly higher impact on the dynamic behavior and structural integrity of the tower compared to damage in the upper sections of the tower. Furthermore, it has been noticed that the effects of tower damage are more pronounced in the first frequency mode, indicating non-linear structural behavior of the tower where the dynamic properties are dependent on the loading conditions. A simple frequency-based damage detection model has been developed based on modal strain energy and validated against measurements on a $3 \mathrm{MW}$ wind turbine. The comparative analysis shows promising results for the detection of a single damage.

Liu [102] developed a new wind turbine rotor-hub-tower system and performed its kinetic analysis. The system is designed for quiescent conditions considering wind wheel gravity, cabin whole gravity, wind tower whole gravity and braced force from the base to the wind turbine, satisfying the law of conservation of energy. The design criteria used is based on random angle and random wind speeds, under maximal and over maximal wind speeds. FEA modelling of the $1.5 \mathrm{MW}$ wind turbine has been carried having a tower height of $63 \mathrm{~m}$. Model analysis results for the first five inherent frequency modes range from $1.13 \mathrm{~Hz}$ to $8.66 \mathrm{~Hz}$, with swing, bending and torsion as the main vibration modes. The feasibility of the developed wind turbine design has been demonstrated. Chen et al. [103] developed and analyzed the structural mechanics of a lattice tubular structure attached to the transition piece, and hence, the tower of the offshore wind turbine (similar to fourlegged jacket). The novel lattice structure does not need any welding. Instead, it uses bolts, which in-turn improves the fatigue strength of the structure. 3D FEA predictions of von Mises's stress distribution and deformations are validated against the experimental findings of Liu [104]. Particle swarm optimization (PSO) algorithm has been employed in order to optimize the shape and size of the lattice tubular structure by obtaining minimum structural weight for given strength, deformation and stability criteria. The loads exerted at top of the lattice structure have been obtained from [104], while the wind loads acting on the tower are obtained from [105]. Iterative results from the PSO algorithm show that a tower having a weight of $119 \mathrm{t}$ and fundamental natural frequency of $0.382 \mathrm{~Hz}$ is the optimal structure. The optimal geometric parameters obtained include $85^{\circ}$ inclination angle of columns and $48.3^{\circ}$ angle of diagonal members relative to horizontal. The resulting turbine has a rated power of 1.5 MW. Table 4 summarizes the review presented in this study on the structural integrity of offshore wind turbines. 
Table 4. Summary of literature review on the structural integrity of offshore wind turbines.

\begin{tabular}{|c|c|c|c|c|}
\hline Component & Methodology & Materials/Structure & Conditions & Key Findings \\
\hline \multirow{3}{*}{ Blades } & FEA & $\begin{array}{l}\text { Fiberglass/epoxy and carbon } \\
\text { Fiber/epoxy composites }\end{array}$ & $\begin{array}{l}\text { NACA4424, camber }=4-14 \% \text {, thickness }=24 \% \text {, } \\
\text { IEC } 61400-01 \text { Class } 1 \text { A loads }\end{array}$ & $\begin{array}{l}\text { Stiffness of carbon fiber/epoxy blades is } 3.7 \text { times higher } \\
\text { than fiberglass/epoxy blades [70] } \\
\text { Maximum flapwise deflection is } 2.9 \mathrm{~m} \text { for critical wind load } \\
\text { conditions [71] }\end{array}$ \\
\hline & FEA/Experimental & $\begin{array}{l}\text { Leading edge protective layer made of } \\
\text { thermoplastic polyurethane }\end{array}$ & $\begin{array}{l}\text { Static and dynamic loading, } 13 \mathrm{~m} \text { long blade, } \\
225 \mathrm{~kW} \text { turbine }\end{array}$ & $\begin{array}{l}\text { ANSYS and ABAQUS underestimate blade edgewise } \\
\text { stiffness; Inclusion of blade protector increases the stiffness } \\
\text { of the blade; At blade tip, von Mises, frictional and tensile } \\
\text { stresses are higher than the yield strength [72-78] }\end{array}$ \\
\hline & GA & $\begin{array}{l}\text { Material density }=1220-1920 \mathrm{~kg} / \mathrm{m}^{3} \\
\mathrm{G}=2-12 \mathrm{GPa}, \mathrm{E}=40-115 \mathrm{GPa}\end{array}$ & $\begin{array}{l}\text { Blade thickness }=15-35 \mathrm{~mm}, 5 \mathrm{MW} \text { turbine, } \\
\text { seismic conditions }\end{array}$ & $\begin{array}{l}\text { Blade material anisotropy leads to higher flapwise and } \\
\text { edgewise stiffness near the root [80] }\end{array}$ \\
\hline \multirow{9}{*}{ Sub-Structure } & Experimental & Gravity-support & Excitation of an active mass damper & Damping ratios $=0.2 \& 2.4 \%$ (first \& second modes) [81] \\
\hline & GA & Gravity-support & Soil properties & Damping ratio is dependent on the soil stiffness [82] \\
\hline & FEA/GA & Monopile & $\begin{array}{l}\text { Integrated optimisation model, } \\
\text { aero-hydro-elastic analyses, } 5 \mathrm{MW} \text { turbine }\end{array}$ & $\begin{array}{l}\text { Frequency }=0.2123 \mathrm{HZ} \text { (first mode); } \\
\text { Deformation }=0.078 \mathrm{~m} \text {; Mass saving }=19.8 \%[83]\end{array}$ \\
\hline & \multirow{4}{*}{ FEA } & Monopile & $\begin{array}{l}\text { IEC } 61400-01 \text { Class } 1 \mathrm{~A} \text { loads, } 78 \mathrm{~m} \text { high tower, } \\
18 \mathrm{~m} \text { long transition piece, } 3 \mathrm{MW} \text { turbine }\end{array}$ & $\begin{array}{l}\text { Maximum deformation, principal stress and elastic strain } \\
\text { occur at the tower head; Monopile substructure avoids } \\
\text { resonance effects [84] }\end{array}$ \\
\hline & & Monopile & $\begin{array}{l}80 \mathrm{~m} \text { high tower, } 3.6 \mathrm{MW} \text { turbine, IEC Class 1A } \\
\text { wind loading, wave loading, tidal loading, } \\
\text { hydrostatic pressure }\end{array}$ & $\begin{array}{l}\text { More stoppers in the transition piece are better for } \\
\text { structural integrity but are costly; Modes } 2 \text { and } 4 \text { are } \\
\text { affected by foundation scouring [86] }\end{array}$ \\
\hline & & Tripod & $\begin{array}{l}6 \mathrm{MW} \text { turbine; tower height }=100 \mathrm{~m} \text {, blades } \\
\text { length }=80.35 \mathrm{~m} \text {, wind, tidal and fatigue loads }\end{array}$ & $\begin{array}{l}\text { Foundation scouring has negligible effects on the natural } \\
\text { frequency, deflection and rotation of the tripod [87] }\end{array}$ \\
\hline & & Jacket & $\begin{array}{l}\text { Artificial Neural Network surrogate modelling, } \\
10 \text { MW turbine }\end{array}$ & $\begin{array}{l}\text { Reliability index indicates turbine life of } 18 \text { years, instead of } \\
22 \text { years calculated theoretically [91] }\end{array}$ \\
\hline & \multirow[t]{2}{*}{ Numerical/Analytical } & Mooring & $\begin{array}{l}200 \mathrm{~m} \text { depth, catenary and taut, clump weight } \\
\text { and buoy, drag and suction }\end{array}$ & $\begin{array}{l}\text { Inclusion of clump weights and buoys are beneficial for } \\
\text { catenary; catenary-taut hybrid mooring is more stable and } \\
\text { cost effective [94] }\end{array}$ \\
\hline & & Mooring & Tension leg, coupled dynamic response model & $\begin{array}{l}\text { Most stable mooring has } 4 \text { legs, } 12 \text { cables and inclination } \\
\text { angle }=30^{\circ}[95]\end{array}$ \\
\hline
\end{tabular}


Table 4. Cont.

\begin{tabular}{|c|c|c|c|c|}
\hline Component & Methodology & Materials/Structure & Conditions & Key Findings \\
\hline \multirow{7}{*}{ Tower } & \multirow{2}{*}{ FSI } & Monopile & Wind, wave and seismic loads & $\begin{array}{l}\text { Rayleigh's energy method is a close approximation of } \\
\text { coupled FSI modelling [97] }\end{array}$ \\
\hline & & Monopile & Concentrated spring model, $5 \mathrm{MW}$ turbine & $\begin{array}{l}\text { Natural frequencies predictive by FAST and ADAMS solver } \\
\text { are in close agreement with SDOF approach [99] }\end{array}$ \\
\hline & \multirow{3}{*}{ FEA } & Monopile & Siemens 2.3 MW turbine, P-y method, & First two bending modes occur at $0.35 \mathrm{~Hz}$ and $1.46 \mathrm{~Hz}$ [98] \\
\hline & & Monopile & $\begin{array}{l}\text { Realistic atmospheric stratifications } 1.5 \mathrm{MW} \\
\text { turbine and } 63 \mathrm{~m} \text { high tower }\end{array}$ & Rotor thrust significantly deflects the tower [100] \\
\hline & & Rotor-hub-tower system & $\begin{array}{l}\text { Wind wheel gravity, cabin whole gravity, wind } \\
\text { tower whole gravity }\end{array}$ & $\begin{array}{l}\text { Swing, bending and torsion are the main vibration } \\
\text { modes [102] }\end{array}$ \\
\hline & Experimental & Tower faults & FDD on a scaled model & $\begin{array}{l}\text { Damage near the bottom of the tower is more impactful } \\
\text { than at the top; the structural response is non-linear [101] }\end{array}$ \\
\hline & PSO & Jacket/lattice tubular & $\begin{array}{l}\text { Loading on lattice and wind loads, } \\
1.5 \mathrm{MW} \text { turbine }\end{array}$ & $\begin{array}{l}\text { Natural frequency }=0.382 \mathrm{~Hz} \text {; optimal columns' inclination } \\
\text { angle }=85^{\circ} \text { and angle of diagonal members }=48.3^{\circ}[103-105]\end{array}$ \\
\hline
\end{tabular}




\section{Offshore Wind Turbines' Maintenance}

G+ Global Offshore Wind Health and Safety Organization publishes annual statistics regarding incidents and accidents occurring globally on offshore wind turbine platforms using an evidence-based approach [106], categorized as potential hazards, near hits, first aid cases, medical injuries, fatalities, asset damage, restricted and lost work-day injuries. The published data shows that in the UK, these incidents and accidents are far more frequent than anywhere else in the world; a total of 469 in the year 2020, which is $~ 63 \%$ of all global incidents in that year. There are two factors that have a significant influence on these statistics. Firstly, the number of offshore wind turbine projects which are under development and operational are considerably more than other European and North American countries, accounting for $\sim 30 \%$ of the global offshore wind energy market (second being China with almost the same market share, but not included in the report). Secondly, the major contribution towards this data comes from near hits and misses, which accounts for $32 \%$ for the UK (USA at 13\%, France and The Netherlands at $6 \%$ each). However, the hazard in the UK is only $8 \%$, compared to $38 \%$ and $37 \%$, respectively, for USA and The Netherlands. Nevertheless, it is of utmost importance to reduce the number of these incidents and accidents, which can be achieved through better work practices and more efficient maintenance strategies for offshore wind turbines.

Corrective and proactive maintenance are widely used maintenance strategies to keep the wind turbine operating and reduce downtime by monitoring their health condition. Corrective maintenance is simple and only implemented once after failure. However, it is not efficient due to a high risk of failed components, leading to severe outcomes. Therefore, time-based preventive maintenance (PM) or condition-based maintenance (CBM) is preferred over corrective maintenance in the offshore wind industry. Reliability is a critical factor for maintenance as low levels of component reliability could lead towards systems failure and extensive maintenance. The choice of correct maintenance strategy is important to maintain constant power generation with minimum downtime, improve performance of offshore wind turbines and reduce total levelized cost of energy (LCoE) [107-109]. Kang et al. [110] reviewed condition-based maintenance strategies for offshore wind energy and presented a summary of existing optimization solutions and maintenance strategies. It has been found that simulation models and intelligence-based solution techniques are widely used and show potential for condition recognition and optimization of offshore wind farm maintenance activities. The operation and maintenance costs of offshore wind farms are higher compared to onshore ones due to difficulty to estimate the actual costs over time. It has been suggested that minimum cost, maximum power generation and maximum availability are three drivers for optimization of maintenance techniques. Due to advancements in electrical and electronic systems for monitoring and analyzing the health of offshore structures, condition-based maintenance is expanding its applications to offshore wind energy sector. Structural health monitoring, acoustic emission testing and vibrations analysis are effective ways to monitor the condition of offshore turbine blades and structures [111].

Dao et al. [112] have proposed an integrated maintenance strategy for offshore wind turbine components by comparing different maintenance strategies. It has been observed that the maintenance downtime due to repairs and delays due to weather conditions have not been considered in previous research studies for condition-based maintenance optimization. The downtime of offshore turbines is approximately double compared to onshore wind turbines due to operating environment, adverse weather conditions and accessibility [107]. The proposed CBMPM strategy reduces the total maintenance cost and downtime of the wind turbine through numerical simulations. Florian and Sørensen [113] have investigated the impact of risk and reliability-based methods on cost of maintenance. Two different preventive approaches have been compared for offshore wind turbine blades. It has been observed that risk-based inspection planning has the potential to reduce the annual maintenance costs and unnecessary repairs compared to a traditional conditionbased strategy. Ambühl and Sørensen [114] have also reported the capability of risk-based 
maintenance planning approaches to optimize maintenance and decrease maintenance expenses. Moreover, this approach has been used to assess the cost impact of incomplete knowledge of input parameters, such as weather forecast, repair time on site, costs and threshold for access, for risk-based maintenance planning. Crude Monte Carlo simulations and different maintenance strategies on a wind farm have been implemented. It has been found that incomplete knowledge of input parameters leads towards inaccurate maintenance decisions and increased costs. The sensitivity studies show a significant influence of uncertainty of weather forecast on maintenance planning, availability and total maintenance costs.

Optimum system reliability of offshore wind turbines depends on a detailed maintenance plan, though maintenance scheduling is complex and challenging [115]. Nguyen and Chou [116] have found a major gap in existing literature on the maintenance schedule of wind turbines. Parameters, such as system reliability, weather conditions, maintenance duration and power generation loss, have been included in the study and the outcome for an individual and grouping maintenance schedules for offshore wind systems investigated. Reduced maintenance costs and improved systems reliability have been obtained for grouping maintenance schedules compared to the baseline schedule, hence the potential for large scale deployment of offshore wind installation in the future. Zhou and Yin [117] have stated the importance of accuracy and comprehensiveness of the maintenance information on maintenance decisions, which have the potential to cause over or under-maintenance of wind turbine components, resulting in increased maintenance costs. A dynamic opportunistic condition-based maintenance strategy has been proposed, integrating predictive analytics to develop optimal maintenance plans for turbine components. Simulation results show that the proposed strategy reduces the maintenance cost by approximately 32.46-39.24\% compared to widely used maintenance strategies. Li et al. [118] have proposed an opportunistic maintenance strategy considering maintenance intervals of each subsystem of an offshore wind turbine and have analyzed the influence of maintenance time schedule in order to decrease the maintenance cost. Optimal maintenance intervals for each subsystem and reduced total maintenance cost compared to conventional maintenance strategy have been obtained. It has thus been recommended to adopt the opportunistic maintenance strategy for offshore wind turbines. Lu et al. [119] have also proposed an opportunistic condition-based maintenance approach to reduce unnecessary maintenance action, maintenance costs and system downtime. Artificial neural network (ANN) has been employed to predict the failure-time distribution of the components and deterioration of offshore wind turbines. It has been concluded that opportunistic condition-based maintenance can provide timely information about components conditions, leading to the lowest expected maintenance cost.

\section{Future Recommendations}

Based on the extensive review of published literature presented here on the recent advancements in offshore wind turbine technology, the aspect that require focus and dedicated scientific efforts of the community are outlined below:

- $\quad$ Due to the multidisciplinary nature of offshore wind turbines, unified design principles at both component-level and system-level are required, and approaches and governing mechanisms are to be examined. This step is very important to build certification strategies for commercial floating offshore wind turbines (FOWTs). Fundamental and applied aspects of FOWTs design will remain a subject of extensive scientific investigations for years to come;

- More systematic in-detail investigations are required to fully understand the dependence of wave loads and excitations of foundational platform of FOWTs. Existing studies only cover a portion of this need;

- $\quad$ Another viable method to develop simple reduced-order models for industrial needs would involve probabilistic determination of wind and hydrodynamic load fac- 
tors and relate them with performance metrics of offshore turbines through other design variables;

- Most of the existing studies involve the turbine rotations for prescribed angular velocities. Thus, our current knowledge lacks in understanding the flow-induced rotations and start-up processes of FOWTs when they operate under intense wave loadings. Such efforts will help us understand how turbine rotation is influenced by yawed flows with oscillating foundations;

- As the aero-hydro-elastic response of floating submersible platforms is inherently nonlinear, the nature of underlying nonlinearities still needs to be revealed. These characteristics will not only assist in developing structures with better damping features, but also it will lead towards designing better nonlinear control techniques;

- Added mass effect plays a critical role in determining the temporal behavior of oscillating structures in dense fluid media, such as water. Its role to stabilize the platforms for both regular and irregular waves should be uncovered;

- Modern reduced-order modeling techniques relying on advanced modal decomposition methods need to be developed for fluid-structure interaction of FOWTs. Such studies will enable the application of machine learning algorithms for optimization of relevant aerodynamic/hydrodynamic processes and structural designs, alongside effective control strategies for FOWTs. In this area, extending the existing techniques to multiphase flows and coupled aerodynamic/hydrodynamic systems will be required;

- Mapping techniques for wind and wave dynamics in installation areas for FOWTs needs to be developed. These can be further coupled with machine learning based controllers to pre-emptively make the systems ready to bear intense loadings. Such active control methodologies would also enable the extraction of more power by stabilizing and controlling foundations adequately in solitary as well as clustered arrangements;

- Existing studies on the structural integrity of FOWTs are very scarce. More dedicated efforts are required in order to evaluate time-dependent structural health of FOWTs, which can lead towards more accurate prediction models for stresses/strains in floating structures subjected to severe weather conditions;

- A better understanding of the complex effects of foundation/soil scouring on the structural health of fixed-support offshore wind turbines is required. This is also very important for the accurate design of mooring cables buried in seabed;

- Offshore structures usually experience extreme weather conditions. Various studies using weather and climatic models have been carried out to understand the impacts of offshore wind farms on local hydrometeorology. Forecasts predicted by these models have several associated uncertainties due to observation time and number, error in the data, measuring inconsistency etc. Ground-based observations, remote sensing and re-analysis products are commonly used to detect and investigate wind farm impacts on ABL's structure and meteorology. More accurate numerical models and algorithms need to be developed to carry out comprehensive analysis.

Author Contributions: Conceptualization, T.A., S.Z.I., A.H. and M.S.U.K.; methodology, T.A., S.Z.I. and M.S.U.K.; formal analysis, T.A., S.Z.I. and M.S.U.K.; investigation, T.A., S.Z.I. and M.S.U.K.; resources, T.A., S.Z.I. and M.S.U.K.; writing—original draft preparation, T.A., S.Z.I. and M.S.U.K.; writing-review and editing, T.A., S.Z.I., A.H. and M.S.U.K.; project administration, T.A. All authors have read and agreed to the published version of the manuscript.

Funding: This research received no external funding.

Institutional Review Board Statement: Not applicable.

Informed Consent Statement: Not applicable.

Conflicts of Interest: The authors declare no conflict of interest. 


\section{References}

1. Musial, W. Overview of Floating Offshore Wind. In Proceedings of the Webinar Hosted by National Renewable Energy Laboratory, Golden, CO, USA, 26 February 2020.

2. Carbon Trust. Offshore Wind Industry Review of GBs: Identifying the Key Barriers to Large Scale Commercialization of Gravity-Based Structures in the Offshore Wind Industry; The Carbon Trust: London, UK, 2015.

3. Bae, Y.; Kim, M.; Kim, H. Performance changes of a floating offshore wind turbine with broken mooring line. Renew. Energy 2017, 101, 364-375. [CrossRef]

4. Gupta, A.; Srishti, A. Offshore Wind Energy Market, 2027; Global Market Insights: Selbyville, DE, USA, 2021.

5. Assets Publicly Shared by Equinor. Available online: https://communicationtoolbox.equinor.com/shared/assets/fd892bb52c744 f66a669? ga=2.163236607.252504396.1634466588-1970887725.1632774422 (accessed on 17 October 2021).

6. Stehly, T.; Beiter, P. 2018 Cost of Wind Energy Review; National Renewable Energy Laboratory: Golden, CO, USA, 2020.

7. Beiter, P.; Musial, W.; Smith, A.; Kilcher, L.; Damiani, R.; Maness, M.; Sirnivas, S.; Stehly, T.; Gevorgian, V. A Spatial-Economic Cost Reduction Pathway Analysis for US Offshore Wind Energy Development from 2015-2030; National Renewable Energy Laboratory: Newport, RI, USA, 2016.

8. Wiser, R.; Rand, J.; Seel, J.; Beiter, P.; Baker, E.; Lantz, E.; Gilman, P. Expert elicitation survey predicts $37 \%$ to $49 \%$ declines in wind energy costs by 2050. Nat. Energy 2021, 6, 555-565. [CrossRef]

9. Röckmann, C.; Lagerveld, S.; Stavenuiter, J. Operation and maintenance costs of offshore wind farms and potential multi-use platforms in the dutch north sea. In Aquaculture Perspective of Multi-Use Sites in the Open Ocean; Buck, B., Langan, R., Eds.; Springer: Cham, Switzerland, 2017.

10. Oguz, E.; Clelland, D.; Day, A.H.; Incecik, A.; López, J.A.; Sánchez, G.; Almeria, G.G. Experimental and numerical analysis of a TLP floating offshore wind turbine. Ocean Eng. 2018, 147, 591-605. [CrossRef]

11. Zhou, Y.; Ning, D.; Shi, W.; Johanning, L.; Liang, D. Hydrodynamic investigation on an OWC wave energy converter integrated into an offshore wind turbine monopile. Coast. Eng. 2020, 162, 103731. [CrossRef]

12. Jang, H.-K.; Park, S.; Kim, M.-H.; Kim, K.-H.; Hong, K. Effects of heave plates on the global performance of a multi-unit floating offshore wind turbine. Renew. Energy 2019, 134, 526-537. [CrossRef]

13. Liu, Y.; Xiao, Q.; Incecik, A.; Peyrard, C. Aeroelastic analysis of a floating offshore wind turbine in platform-induced surge motion using a fully coupled CFD-MBD method. Wind Energy 2019, 22, 1-20. [CrossRef]

14. Kyle, R.; Lee, Y.C.; Früh, W.-G. Propeller and vortex ring state for floating offshore wind turbines during surge. Renew. Energy 2020, 155, 645-657. [CrossRef]

15. Shi, W.; Jiang, J.; Sun, K.; Ju, Q. Aerodynamic performance of semi-submersible floating wind turbine under pitch motion. Sustain. Energy Technol. Assess. 2021, 48, 101556. [CrossRef]

16. Lei, H.; Zhou, D.; Bao, Y.; Chen, C.; Ma, N.; Han, Z. Numerical simulations of the unsteady aerodynamics of a floating vertical axis wind turbine in surge motion. Energy 2017, 127, 1-17. [CrossRef]

17. Lei, H.; Zhou, D.; Lu, J.; Chen, C.; Han, Z.; Bao, Y. The impact of pitch motion of a platform on the aerodynamic performance of a floating vertical axis wind turbine. Energy 2017, 119, 369-383. [CrossRef]

18. Lei, H.; Su, J.; Bao, Y.; Chen, Y.; Han, Z.; Zhou, D. Investigation of wake characteristics for the offshore floating vertical axis wind turbines in pitch and surge motions of platforms. Energy 2019, 166, 471-489. [CrossRef]

19. Liu, Y.; Xiao, Q.; Incecik, A.; Peyrard, C.; Wan, D. Establishing a fully coupled CFD analysis tool for floating offshore wind turbines. Renew. Energy 2017, 112, 280-301. [CrossRef]

20. Bashetty, S.; Ozcelik, S. Review on Dynamics of Offshore Floating Wind Turbine Platforms. Energies 2021, 14, 6026. [CrossRef]

21. Chen, J.; Hu, Z.; Liu, G.; Wan, D. Coupled aero-hydro-servo-elastic methods for floating wind turbines. Renew. Energy 2019, 130, 139-153. [CrossRef]

22. Morison, J.R.; Johnson, J.W.; Schaaf, S.A. The force exerted by surface waves on piles. J. Pet. Technol. 1950, 2, 149-154. [CrossRef]

23. Dafnakis, P.; Bhalla, A.P.S.; Sirigu, S.A.; Bonfanti, M.; Bracco, G.; Mattiazzo, G. Comparison of wave-structure interaction dynamics of a submerged cylindrical point absorber with three degrees of freedom using potential flow and computational fluid dynamics models. Phys. Fluids 2020, 32, 093307. [CrossRef]

24. Rezaeiha, A.; Micallef, D. Wake interactions of two tandem floating offshore wind turbines: CFD analysis using actuator disc model. Renew. Energy 2021, 179, 859-876. [CrossRef]

25. Cheng, P.; Huang, Y.; Wan, D. A numerical model for fully coupled aero-hydrodynamic analysis of floating offshore wind turbine. Ocean Eng. 2018, 173, 183-196. [CrossRef]

26. Cormier, M.; Caboni, M.; Lutz, T.; Boorsma, K.; Krämer, E. Numerical analysis of unsteady aerodynamics of floating offshore wind turbines. J. Phys. Conf. Ser. 2018, 1037, 072048. [CrossRef]

27. Naderi, S.; Parvanehmasiha, S.; Torabi, F. Modeling of horizontal axis wind turbine wakes in Horns Rev offshore wind farm using an improved actuator disc model coupled with computational fluid dynamic. Energy Convers. Manag. 2018, 171, 953-968. [CrossRef]

28. Richmond, M.; Antoniadis, A.; Wang, L.; Kolios, A.; Al-Sanad, S.; Parol, J. Evaluation of an offshore wind farm computational fluid dynamics model against operational site data. Ocean Eng. 2019, 193, 106579. [CrossRef]

29. Tran, T.T.; Kim, D.-H. A CFD study of coupled aerodynamic-hydrodynamic loads on a semisubmersible floating offshore wind turbine. Wind Energy 2017, 21, 70-85. [CrossRef] 
30. Gargallo-Peiró, A.; Avila, M.; Owen, H.; Prieto-Godino, L.; Folch, A. Mesh generation, sizing and convergence for onshore and offshore wind farm Atmospheric Boundary Layer flow simulation with actuator discs. J. Comput. Phys. 2018, 375, $209-227$. [CrossRef]

31. Li, L.; Huang, Z.; Ge, M.; Zhang, Q. A novel three-dimensional analytical model of the added streamwise turbulence intensity for wind-turbine wakes. Energy 2021, 238, 121806. [CrossRef]

32. Fang, Y.; Duan, L.; Han, Z.; Zhao, Y.; Yang, H. Numerical analysis of aerodynamic performance of a floating offshore wind turbine under pitch motion. Energy 2020, 192, 116621. [CrossRef]

33. Bangga, G.; Guma, G.; Lutz, T.; Krämer, E. Numerical simulations of a large offshore wind turbine exposed to turbulent inflow conditions. Wind Eng. 2018, 42, 88-96. [CrossRef]

34. Liu, Y.; Chen, D.; Li, S. The artificial generation of the equilibrium marine atmospheric boundary layer for the CFD simulation of offshore wind turbines. J. Wind Eng. Ind. Aerodyn. 2018, 183, 44-54. [CrossRef]

35. Li, L.; Liu, Y.; Yuan, Z.; Gao, Y. Wind field effect on the power generation and aerodynamic performance of offshore floating wind turbines. Energy 2018, 157, 379-390. [CrossRef]

36. Zhou, Y.; Xiao, Q.; Liu, Y.; Incecik, A.; Peyrard, C.; Wan, D.; Li, S. A CFD Study for Floating Offshore Wind Turbine Aerodynamics in Turbulent Wind Field. In Proceedings of the Virtual ASME 3rd International Offshore Wind Technical Conference, Online, 16-17 February 2021.

37. Sirnivas, S.; Musial, W.; Bailey, B.; Filippelli, M. Assessment of Offshore Wind System Design, Safety, and Operation Standards; National Renewable Energy Laboratory: Golden, CO, USA, 2014.

38. Wen, B.; Tian, X.; Dong, X.; Peng, Z.; Zhang, W.; Wei, K. A numerical study on the angle of attack to the blade of a horizontal-axis offshore floating wind turbine under static and dynamic yawed conditions. Energy 2019, 168, 1138-1156. [CrossRef]

39. Shen, X.; Chen, J.; Hu, P.; Zhu, X.; Du, Z. Study of the unsteady aerodynamics of floating wind turbines. Energy 2018, 145, 793-809. [CrossRef]

40. Dong, J.; Viré, A. Comparative analysis of different criteria for the prediction of vortex ring state of floating offshore wind turbines Renew. Energy 2021, 163, 882-909. [CrossRef]

41. Wen, B.; Beng, X.; Tian, X.; Peng, Z.; Zhang, W.; Wei, K. The power performance of an offshore floating wind turbine in platform pitching motion. Energy 2018, 154, 508-521. [CrossRef]

42. Wen, B.; Tian, X.; Dong, X.; Peng, Z.; Zhang, W. Influences of surge motion on the power and thrust characteristics of an offshore floating wind turbine. Energy 2017, 141, 2054-2068. [CrossRef]

43. Bruinsma, N.; Paulsen, B.T.; Jacobsen, N.G. Validation and application of a fully nonlinear numerical wave tank for simulating floating offshore wind turbines. Ocean Eng. 2018, 147, 647-658. [CrossRef]

44. Lee, H.; Lee, D.J. Effects of platform motions on aerodynamic performance and unsteady wake evolution of a floating offshore wind turbine. Renew. Energy 2019, 143, 9-23. [CrossRef]

45. Zhang, Y.; Kim, B. A Fully Coupled Computational Fluid Dynamics Method for Analysis of Semi-Submersible Floating Offshore Wind Turbines Under Wind-Wave Excitation Conditions Based on OC5 Data. Appl. Sci. 2018, 8, 2314. [CrossRef]

46. Lin, L.; Wang, K.; Vassalos, D. Detecting wake performance of floating offshore wind turbine. Ocean Eng. 2018, 156, $263-276$. [CrossRef]

47. Chen, Z.; Wang, X.; Guo, Y.; Kang, S. Numerical analysis of unsteady aerodynamic performance of floating offshore wind turbine under platform surge and pitch motions. Renew. Energy 2021, 163, 1849-1870. [CrossRef]

48. Jonkman, J.M. Dynamics of offshore floating wind turbines-model development and verification. Wind Energy 2009, 12, 459-492 [CrossRef]

49. Coulling, A.J.; Goupee, A.J.; Robertson, A.; Jonkman, J.; Dagher, H.J. Validation of a FAST semi-submersible floating wind turbine numerical model with DeepCwind test data. J. Renew. Sustain. Energy 2013, 5, 023116. [CrossRef]

50. Lienard, C.; Boisard, R.; Daudin, C. Aerodynamic behavior of a floating offshore wind turbine. AIAA J. 2020, 58, 3835-3847. [CrossRef]

51. Lemmer, F.; Yu, W.; Cheng, P.W. Iterative frequency-domain response of floating offshore wind turbines with parametric drag. J. Mar. Sci. Eng. 2018, 6, 118. [CrossRef]

52. Zhang, P.; Yang, S.; Li, Y.; Gu, J.; Hu, Z.; Zhang, R.; Tang, Y. Dynamic Response of Articulated Offshore Wind Turbines under Different Water Depths. Energies 2020, 13, 2784. [CrossRef]

53. Chuang, Z.; Liu, S.; Lu, Y. Influence of second order wave excitation loads on coupled response of an offshore floating wind turbine. Int. J. Nav. Arch. Ocean Eng. 2020, 12, 367-375. [CrossRef]

54. Alkarem, Y.R.; Ozbahceci, B.O. A complemental analysis of wave irregularity effect on the hydrodynamic response of offshore wind turbine with the semi-submersible platform. Appl. Ocean Res. 2021, 113, 102757. [CrossRef]

55. Li, H.; Bachynski-Polić, E.E. Validation and application of nonlinear hydrodynamics from CFD in an engineering model of a semi-submersible floating wind turbine. Mar. Struct. 2021, 79, 103054. [CrossRef]

56. Wang, L.; Robertson, A.; Jonkman, J.; Yu, Y.; Koop, A.; Borràs Nadal, A.; Li, H.; Shi, W.; Pinguet, R.; Zhou, Y.; et al. Investigation of nonlinear difference-frequency wave excitation on a semisubmersible offshore-wind platform with bichromatic-wave CFD simulations. In Proceedings of the Virtual ASME 3rd International Offshore Wind Technical Conference, Online, 16-17 February 2021. 
57. Martini, F.; Montoya, L.T.C.; Ilinca, A. Review of wind turbine icing modelling approaches. Energies 2021, 14, 5207. [CrossRef]

58. Yue, W.; Xue, Y.; Liu, Y. High Humidity Aerodynamic Effects Study on Offshore Wind Turbine Airfoil/Blade Performance through CFD Analysis. Int. J. Rotating Mach. 2017, 2017, 1-15. [CrossRef]

59. Lagdani, O.; Tarfaoui, M.; Nachtane, M.; Trihi, M.; Laaouidi, H. A numerical investigation of the effects of ice accretion on the aerodynamic and structural behavior of offshore wind turbine blade. Wind Eng. 2020, 45, 1433-1446. [CrossRef]

60. Fleming, P.A.; Gebraad, P.M.; Lee, S.; van Wingerden, J.W.; Johnson, K.; Churchfield, M.; Michalakes, J.; Spalart, P.; Moriarty, P. Evaluating techniques for redirecting turbine wakes using SOWFA. Renew. Energy 2014, 70, 211-218. [CrossRef]

61. Fleming, P.A.; Gebraad, P.M.; Lee, S.; van Wingerden, J.W.; Johnson, K.; Churchfield, M.; Michalakes, J.; Spalart, P.; Moriarty, P. Simulation comparison of wake mitigation control strategies for a two-turbine case. Wind Energy 2015, 18, 2135-2143. [CrossRef]

62. Fleming, P.; Annoni, J.; Shah, J.J.; Wang, L.; Ananthan, S.; Zhang, Z.; Hutchings, K.; Wang, P.; Chen, W.; Chen, L. Field test of wake steering at an offshore wind farm. Wind Energy Sci. 2017, 2, 229-239. [CrossRef]

63. Sang, L.Q.; Li, Q.; Cai, C.; Maeda, T.; Kamada, Y.; Wang, X.; Zhou, S.; Zhang, F. Wind tunnel and numerical study of a floating offshore wind turbine based on the cyclic pitch control. Renew. Energy 2021, 172, 453-464. [CrossRef]

64. Whittlesey, R.W.; Liska, S.; Dabiri, J.O. Fish schooling as a basis for vertical axis wind turbine farm design. Bioinspiration Biomim. 2010, 5, 035005. [CrossRef] [PubMed]

65. Zhang, M.; Arendshorst, M.G.; Stevens, R.J. Large eddy simulations of the effect of vertical staggering in large wind farms. Wind Energy 2019, 22, 189-204. [CrossRef]

66. Neunaber, I.; Hölling, M.; Stevens, R.J.; Schepers, G.; Peinke, J. Distinct turbulent regions in the wake of a wind turbine and their inflow-dependent locations: The creation of a wake map. Energies 2020, 13, 5392. [CrossRef]

67. Wang, Y.; Miao, W.; Ding, Q.; Li, C.; Xiang, B. Numerical investigations on control strategies of wake deviation for large wind turbines in an offshore wind farm. Ocean Eng. 2019, 173, 794-801. [CrossRef]

68. Klein, L.; Gude, J.; Wenz, F.; Lutz, T.; Krämer, E. Advanced computational fluid dynamics (CFD)-multi-body simulation (MBS) coupling to assess low-frequency emissions from wind turbines. Wind Energy Sci. 2018, 3, 713-728. [CrossRef]

69. May, R.; Nygård, T.; Falkdalen, U.; Åström, J.; Hamre, Ø.; Stokke, B.G. Paint it black: Efficacy of increased wind turbine rotor blade visibility to reduce avian fatalities. Ecol. Evol. 2020, 10, 8927-8935. [CrossRef]

70. Boudounit, H.; Tarfaoui, M.; Saifaoui, D.; Nachtane, M. Structural analysis of offshore wind turbine blades using finite element method. Wind Eng. 2019, 44, 168-180. [CrossRef]

71. Hashin, Z. Failure criteria for unidirectional fiber composites. J. Appl. Mech. 1980, 47, 329-334. [CrossRef]

72. Hashin, Z.; Rotem, A. A fatigue failure criterion for fiber reinforced materials. J. Compos. Mater. 1973, 7, 448-464. [CrossRef]

73. Hand, B.; Kelly, G.; Cashman, A. Structural analysis of an offshore vertical axis wind turbine composite blade experiencing an extreme wind load. Mar. Struct. 2021, 75, 102858. [CrossRef]

74. IEC. Wind Turbines_Part 1: Design Requirements; International Electrotechnical Commission: Geneva, Switzerland, 2005.

75. Finnegan, W.; Jiang, Y.; Dumergue, N.; Davies, P.; Goggins, J. Investigation and validation of numerical models for composite wind turbine blades. J. Mar. Sci. Eng. 2021, 9, 525. [CrossRef]

76. Finnegan, W.; Keeryadath, P.D.; Coistealbha, R.O.; Flanagan, T.; Flanagan, M.; Goggins, J. Development of a numerical model of a novel leading edge protection component for wind turbine blades. Wind Energy Sci. 2020, 5, 1567-1577. [CrossRef]

77. Finnegan, W.; Flanagan, T.; Goggins, J. Development of a Novel Solution for Leading Edge Erosion on Offshore Wind Turbine Blades. In Proceedings of the 13th International Conference on Damage Assessment of Structures, Porto, Portugal, 9-10 July 2019.

78. Fagan, E.M.; Flanagan, M.; Leen, S.B.; Flanagan, T.; Doyle, A.; Goggins, J. Physical experimental static testing and structural design optimisation for a composite wind turbine blade. Compos. Struct. 2017, 164, 90-103. [CrossRef]

79. Navadeh, N.; Goroshko, I.; Zhuk, Y.; Moghadam, F.E.; Fallah, A.S. Finite Element Analysis of Wind Turbine Blade Vibrations. Vibration 2021, 4, 310-322. [CrossRef]

80. Ali, A.; De Risi, R.; Sextos, A. Finite element modeling optimization of wind turbine blades from an earthquake engineering perspective. Eng. Struct. 2020, 222, 111105. [CrossRef]

81. Oh, S.; Ishihara, T. Structural parameter identification of a $2.4 \mathrm{MW}$ bottom fixed wind turbine by excitation test using active mass damper. Wind Energy 2018, 21, 1232-1238. [CrossRef]

82. Ishihara, T.; Wang, L. A study of modal damping for offshore wind turbines considering soil properties and foundation types. Wind Energy 2019, 22, 1760-1778. [CrossRef]

83. Gentils, T.; Wang, L.; Kolios, A. Integrated structural optimisation of offshore wind turbine support structures based on finite element analysis and genetic algorithm. Appl. Energy 2017, 199, 187-204. [CrossRef]

84. Ram, S.L.; Mohana, R. Simulation and numerical analysis of offshore wind turbine with monopile foundation. IOP Conf. Ser. Mater. Sci. Eng. 2020, 872, 012046.

85. Det Norske Vertias. Design of Offshore Wind Turbine Structures; Det Norske Veritas AS: Hovik, Norway, 2014.

86. Luengo, M.M.; Kolios, A.; Wang, L. Parametric FEA modelling of offshore wind turbine support structures: Towards scaling-up and CAPEX reduction. Intl. J. Mar. Energy 2017, 19, 16-31. [CrossRef]

87. Ma, H.; Yang, J.; Chen, L. Effect of scour on the structural response of an offshore wind turbine supported on tripod foundation Appl. Ocean Res. 2018, 73, 179-189. [CrossRef] 
88. Zhongming, Z.; Linong, L.; Wangqiang, Z.; Wei, L. The National Basic Research Program of China (2014CB046200); Nan Jing University of Aeronautics and Astronautics: Nanjing, China, 2015.

89. Stahlmann, A. Experimental and Numerical Modeling of Scour at Offshore Wind Turbines. Ph.D. Thesis, Leibniz University, Hannover, Germany, 2013.

90. Stuyts, B.; Cathie, D. Scour Assessment and Measurement for Pile-Supported Wind Turbine Foundations. In Proceedings of the 32nd International Conference on Ocean, Offshore and Arctic Engineering, Nantes, France, 9-14 June 2013.

91. Shittu, A.A.; Mehmanparast, A.; Shafiee, M.; Kolios, A.; Hart, P.; Pilario, K. Structural reliability assessment of offshore wind turbine support structures subjected to pitting corrosion-fatigue: A damage tolerance modelling approach. Wind Energy 2020, 23, 2004-2026. [CrossRef]

92. Ghigo, A.; Cottura, L.; Caradonna, R.; Bracco, G.; Mattiazzo, G. Platform optimization and cost analysis in a floating offshore wind farm. J. Mar. Sci. Eng. 2020, 8, 835. [CrossRef]

93. Techet, A.H. Hydrodynamics for Ocean Engineers; MIT Department of Ocean Engineering: Cambridge, MA, USA, 2004.

94. Xu, K.; Larsen, K.; Shao, Y.; Zhang, M.; Gao, Z.; Moan, T. Design and comparative analysis of alternative mooring systems for floating wind turbines in shallow water with emphasis on ultimate limit state design. Ocean Eng. 2021, 219, 108377. [CrossRef]

95. Huang, W.H.; Yang, R.Y. Water depth variation influence on the mooring line design for FOWT within shallow water region. J. Mar. Sci. Eng. 2021, 9, 409. [CrossRef]

96. Li, Y.; Le, C.; Ding, H.; Zhang, P.; Zhang, J. Dynamic response for a submerged floating offshore wind turbine with different mooring configurations. J. Mar. Sci. Eng. 2019, 7, 115. [CrossRef]

97. Dagli, B.Y.; Tuskan, Y.; Gokkus, U. Evaluation of offshore wind turbine tower dynamics with numerical analysis. Adv. Civ. Eng. 2018, 2018, 3054851. [CrossRef]

98. Asnaashari, E.; Morris, A.; Andrew, I.; Hahn, W.; Sinha, J.K. Finite element modelling and in-situ modal testing of an offshore wind turbine. J. Vib. Eng. Technol. 2018, 6, 101-106. [CrossRef]

99. Ko, Y.Y. A simplified structural model for monopile-supported offshore wind turbines with tapered towers. Renew. Energy 2020, 156, 777-790. [CrossRef]

100. Feliciano, J.; Cortina, G.; Spear, A.; Calaf, M. Generalized analytical displacement model for wind turbine towers under aerodynamic loading. J. Wind Eng. Ind. Aerodyn. 2018, 176, 120-130. [CrossRef]

101. .Kim, W.; Yi, J.-H.; Kim, J.-T.; Park, J.-H. Vibration-based Structural Health Assessment of a Wind Turbine Tower Using a Wind Turbine Model. Procedia Eng. 2017, 188, 333-339. [CrossRef]

102. Liu, W. Design and kinetic analysis of wind turbine blade-hub-tower coupled system. Renew. Energy 2016, 94, 547-557. [CrossRef]

103. Chen, J.; Yang, R.; Ma, R.; Li, J. Design optimization of wind turbine tower with lattice-tubular hybrid structure using particle swarm algorithm. Struct. Des. Tall Spéc. Build. 2016, 25, 743-758. [CrossRef]

104. Germanischer, L. ; Wind Energy Committee. Guideline for the Certification of Wind Turbines; Germanishcer Loyd: Hamburg, Germany, 2010.

105. National Standard of The People's Republic of China. Load Code for the Design of Buildings; GB 50009; The General Administration of Quality Supervision, Inspection and Quarantine of the People's Republic of China, The Standardization Administration of the People's Republic of China: Beijing, China, 2012.

106. Energy Institute. G+ Global Offshore Wind Health and Safety Organization: 2020 Incident Data Report; EI: Bedfordshire, UK, 2021.

107. Dao, C.D.; Kazemtabrizi, B.; Crabtree, C.J. Wind turbine reliability data review and impacts on levelized cost of energy. Wind Energy 2019, 22, 1848-1871. [CrossRef]

108. Carroll, J.; McDonald, A.; McMillan, D. Failure rate, repair time and unscheduled O\&M cost analysis of offshore wind turbines. Wind Energy 2016, 19, 1107-1119.

109. Reder, M.D.; Gonzalez, E.; Melero, J.J. Wind turbine failures-Tackling current problems in failure data analysis. J. Phys. Conf. Ser. 2016, 753, 072027. [CrossRef]

110. Kang, J.; Sobra, I.J.; Soares, C.G. Review of Condition-Based Maintenance Strategies for Offshore Wind Energy. J. Mar. Sci. Appl. 2019, 18, 1-16. [CrossRef]

111. Liu, K.; Yan, R.-J.; Soares, C.G. Damage identification in offshore jacket structures based on modal flexibility. Ocean Eng. 2018, 170, 171-185. [CrossRef]

112. Dao, C.D.; Kazemtabrizi, B.; Crabtree, C.J.; Tavner, P.J. Integrated condition-based maintenance modelling and optimisation for offshore wind turbines. Wind Energy 2021, 24, 1180-1198. [CrossRef]

113. Florian, M.; Sørensen, J.D. Risk-based planning of operation and maintenance for offshore wind farms. Energy Procedia 2017, 137, 261-272. [CrossRef]

114. Ambühl, S.; Sørensen, J.D. Sensitivity of Risk-Based Maintenance Planning of Offshore Wind Turbine Farms. Energies 2017, 10, 505. [CrossRef]

115. Shafiee, M. Maintenance logistics organization for offshore wind energy: Current progress and future perspectives. Renew. Energy 2015, 77, 182-193. [CrossRef]

116. Nguyen, T.A.T.; Chou, S.-Y. Maintenance strategy selection for improving cost-effectiveness of offshore wind systems. Energy Convers. Manag. 2018, 157, 86-95. [CrossRef] 
117. Zhou, P.; Yin, P. An opportunistic condition-based maintenance strategy for offshore wind farm based on predictive analytics. Renew. Sustain. Energy Rev. 2019, 109, 1-9. [CrossRef]

118. Li, M.; Wang, M.; Kang, J.; Sun, L.; Jin, P. An opportunistic maintenance strategy for offshore wind turbine system considering optimal maintenance intervals of subsystems. Ocean Eng. 2020, 216, 108067. [CrossRef]

119. Lu, Y.; Sun, L.; Zhang, X.; Feng, F.; Kang, J.; Fu, G. Condition based maintenance optimization for offshore wind turbine considering opportunities based on neural network approach. Appl. Ocean Res. 2018, 74, 69-79. [CrossRef] 